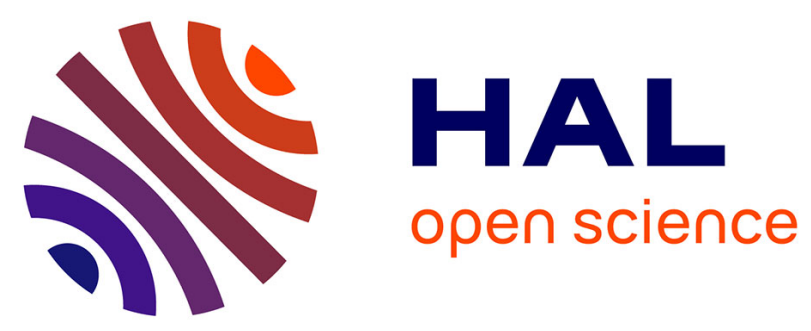

\title{
Longitudinal profile optimization for roads within an eco-design framework
}

Pierre-Olivier Vandanjon, Emmanuel Vinot, Véronique Cerezo, Alex Coiret, Michel Dauvergne, Mohamed Bouteldja

\section{- To cite this version:}

Pierre-Olivier Vandanjon, Emmanuel Vinot, Véronique Cerezo, Alex Coiret, Michel Dauvergne, et al.. Longitudinal profile optimization for roads within an eco-design framework. Transportation Research Part D: Transport and Environment, 2019, 67, p. 642-658. 10.1016/j.trd.2019.01.002 . hal-02005356v2

\author{
HAL Id: hal-02005356 \\ https://hal.science/hal-02005356v2
}

Submitted on 21 Dec 2020

HAL is a multi-disciplinary open access archive for the deposit and dissemination of scientific research documents, whether they are published or not. The documents may come from teaching and research institutions in France or abroad, or from public or private research centers.
L'archive ouverte pluridisciplinaire HAL, est destinée au dépôt et à la diffusion de documents scientifiques de niveau recherche, publiés ou non, émanant des établissements d'enseignement et de recherche français ou étrangers, des laboratoires publics ou privés. 
This is the Authors post print version of the final paper published in

Transportation Research Part D: Transport and Environment

https://doi.org/10.1016/j.trd.2019.01.002

\title{
Longitudinal Profile Optimization for Roads within an Eco-design Framework
}

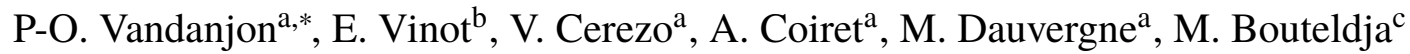 \\ aIfsttar, Ame-Ease, Allée des Ponts et Chaussées, F-44341 Bouguenais, France \\ ${ }^{b}$ Ifsttar, Ame-Eco7, 25 Avenue François Mitterrand, F-69675, Bron, France \\ ${ }^{c}$ Cerema, DTerCE, Laboratoire de Lyon, 25 Avenue François Mitterrand, F-69675, Bron, France
}

\begin{abstract}
This paper proposes a methodology to optimize the longitudinal profile of roads according to either an energy consumption or Global Warming Potential (GWP) criterion calculated for both construction and operation phases. For the construction phase assessment, this methodology is based on a earthworks model that computes the geometric differences between the natural terrain and the longitudinal road profile and moreover uses environmental data validated with real experiments. The operation phase is assessed by simulating traffic over a ten-years period. Traffic simulations are based on vehicle dynamic models, also validated with real experiments. The optimization problem is set up in a finite dimensional optimization. A case study illustrates this methodology. By taking into account actual traffic measurements, the optimized profile decreases by $6 \%$ the total primary energy consumption and by $8 \%$ the GWP.
\end{abstract}

Keywords: Energy, GWP, Road, Optimization, Dynamic Model

\section{Introduction}

In the future, according to the International Transport Forum (ITF) 2017 report for the Organization for Economic Cooperation and Development (OECD), GreenHouse Gas (GHG) emissions from transportation should increase by $60 \%$ between 2015 and 2050 (ITF (2017)). During this same period (2010 - 2050), in order to maintain the global warming below $1.5^{\circ} \mathrm{C}$, experts from the Intergovernmental Panel on Climate Change (IPPC) advise keeping the GHG emissions from transportation constant (Meyer et al. 2014). It has thus become necessary to explore new leads in order to achieve this objective of GHG emissions for 2050. This goal has stimulated recent developments in the assessment of the environmental impacts of road infrastructure within Life

\footnotetext{
*corresponding author

Email address: pierre-olivier.vandanjon@ifsttar.fr (P-O. Vandanjon)
} 
Cycle Assessment (LCA) and Life Cycle Costs (LCC) framework. An LCA analysis considers several steps in the life of road infrastructure: planning/design, construction, maintenance, operations and end-of-life. Most researches conducted on assessment have focused on the construction and maintenance phases since these steps are fully controlled by road builders and operators. Recent research however revealed that the operation phase can account for up to $97 \%$ of the facility energy consumption and $95 \%$ of its GHG emissions when considering a 30-years lifetime, which is common in road structure sizing (Jullien et al. 2015a). When comparing two infrastructure projects, the operation phase can become decisive. An accurate assessment of this phase is thus required.

In the automotive field, the road is often viewed as an invariant of the vehicle-infrastructuredriver system. Numerous studies have focused on limiting vehicle fuel consumption while investigating the benefits of vehicle enhancements or eco-driving behavior (for passenger cars: Kamal et al. (2011), for trucks: Huang et al. (2008)). Studies conducted on the influence of road characteristics on fuel consumption are not as prevalent (Hammarström et al. 2012) and mainly address rolling resistance (Bryce et al. 2014). The seminal work by Webb (1952) on the effect of longitudinal road grade on fuel consumption is interesting from a historical perspective.

Our approach here is different since this work focuses on the impact of road geometry on the operation phase energy demand. Such an approach is more widespread in the civil engineering field, where the road is considered as a design variable. The objective is generally minimizing the construction costs while maintaining satisfactory comfort and safety performances (Chew et al. 1989). National design guidelines summarize good practices and provide limitations for the geometric characteristics such as the Guide for Road Design from American Association of State Highway and Transportation Officials, Austroads (Association of Australasian Road Transport Agencies) or the French ARP and ICTAAL (AASHTO 1994; Setra 2000). Nevertheless, classical design methods are mainly based on economical cost assessments from the seminal paper by Monge (1781) to the more recent books in road design (e.g. Jha et al. (2006)). Moreover, it appears that energy demand during the operation phase can indeed be taken into account but in a very simplistic way. In Jong and Schonfeld (2001), fuel consumption is estimated from both average running speed and longitudinal road slope using regression models. More recently, Kang et al. (2011) included fuel consumption in the vehicle operating costs which are derived from applying vehicle-mile ratios to the length of road infrastructure and certain traffic information (traffic flow, travel time, and speed). The approach proposed herein is more accurate since it uses vehicle dynamics models.

In the environmental field, road impacts are assessed to obtain a more general view and are mainly based on simplified statistical models. Along these lines, Ragione and Giovanni (2016), Sentoff et al. (2015) and Wyatt et al. (2014) highlighted the importance of taking into account longitudinal road slope in models that assess the environmental impacts. Nevertheless, longitudinal road slope is always considered as a constant input. More recently, Davey et al. (2017) proposed optimizing road design based on the basis of ecological considerations.

In this work, we apply an optimization methodology for road energy demand based on a specific variable, namely the longitudinal road profile. This methodology includes vehicle simulations, which are based on accurate and sensitive dynamic models and engine models validated using real data. The present paper thus proposes an original approach, that establishes a strong link between 
the civil engineering and automotive fields.

After describing the methodology and assumptions introduced to establish the optimization process, the paper will present the framework for assessment of the construction and operation phases. Next, the optimization method will be detailed. Lastly, the method will be applied to a case study and a discussion of results will be provided .

\section{Methodology}

The methodology developed herein, called "Sloop" for slope optimization, lies within the Eco-design framework, which is viewed as an infrastructure design optimization process. The optimization criteria consist of the assessment-related outputs of each phase of the infrastructure life-cycle (see the green arrows in Figure 1 pointing to the optimization cell). Degrees of freedom of the optimization are design parameters. This assessment is based on the impacts (red arrows) or resource consumption (blue arrows) of each infrastructure life-cycle phase, with, maintenance feeding back into the operations phase. With respect to the environmental impact assessment, two life cycle phases are taken into account: construction and operations. The optimization criteria are selected among classical life-cycle environmental impact indicators. The degrees of freedom of this optimization process consist of geometric characteristics (longitudinal slope, cross-fall, radius of curvature), as well as with surface characteristics (texture in relation to rolling resistance) or materials. The adequacy of this type of approach has been demonstrated in comparing two variants for the case of High Speed Rail Line project (Bosquet et al. 2014).

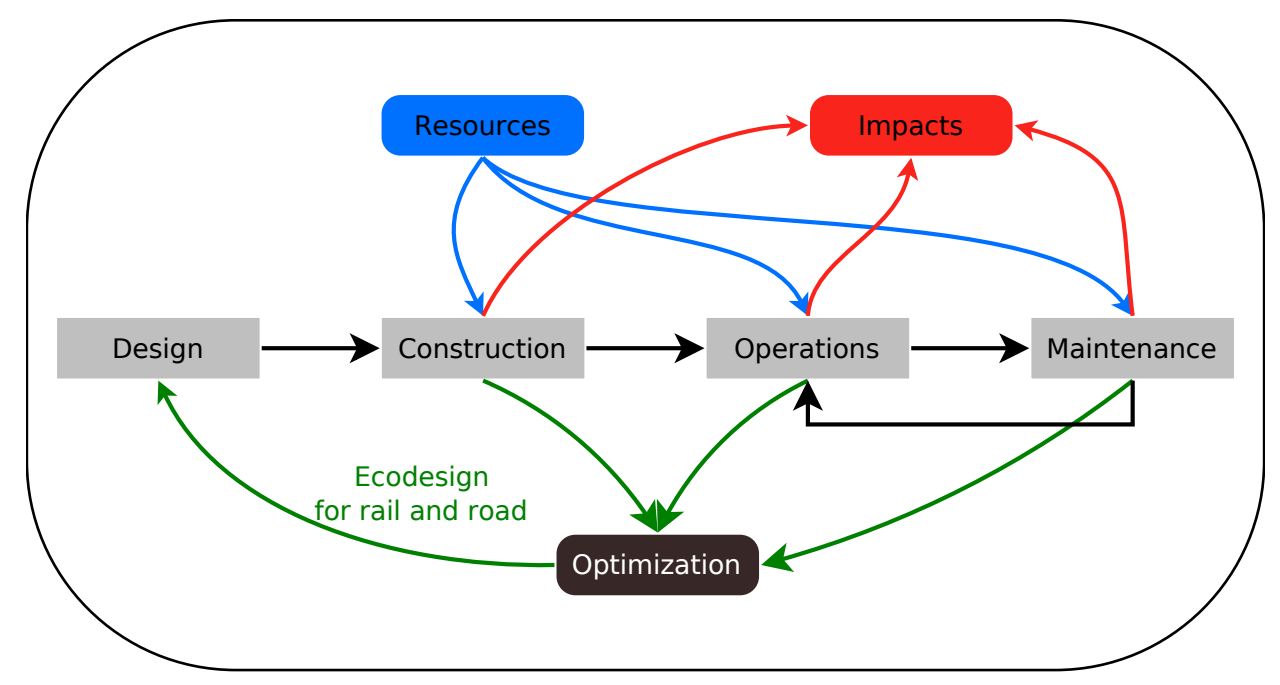

Figure 1. Framework of the infrastructure design optimization process based on a life cycle assessment

This study focuses on primary energy consumption and global warming potential (GWP) minimization. These indicators are robust, validated by the scientific community and standardized. The degree of freedom is the longitudinal profile of the road. The initial profile is provided by technical draftsmen. Sloop performs a local optimization around this initial profile. It is assumed 
that the optimized profile is not very different from the initial profile. Under this assumption, the maintenance phase is considered to be the same regardless of the longitudinal road profile. Similarly, the pavement layers are assumed to be the same for each profile. The construction phase is then primarily assessed by examining the earthworks, which are estimated by computing geometric variations between the natural terrain and the longitudinal profile. The operations phase is assessed by simulating traffic over a ten-years period (this choice of duration is discussed at the end of the paper).

\subsection{Life Cycle Analysis: System description}

The environmental impact assessment is carried out according to the standardized life cycle analysis methodology (ISO 2006a,b). The objective therein is to obtain impact indicators values that correlate the earthmoving phase of a new road with the operations phase on the same road for a given period of time. The functional unit studied is defined so as "to enable the circulation of a certain level of vehicle traffic over a given road section for 10 years". Both the system and boundary conditions are described in Figure 2. Some processes are not considered in the global assessment since they produce the same impact independent of the longitudinal road profile under the assumption that the considered profiles are not too much different:

- Road pavement structure (i.e. layer composition and thickness);

- Road maintenance sequences;

- Construction of plants, machinery and vehicles used to build and transport materials;

- Construction of the vehicles traveling the given road section.

In this paper, only primary energy consumption and global warming potential are considered. Following Wang et al. (2016), the upstream part of energy and carbon footprint tied to fuel production is considered in both construction and operation phases of LCA. The indicator for 100-year global warming potential is calculated according to the IPCC 2007 method (IPCC 2007). Regarding the construction phase, life cycle inventories used for earthmoving impact assessments stem from the ECORCE M (ECO comparator applied to Road Construction and Maintenance) database. They are described in the tool reference manual (Jullien et al. 2015b). These inventories include the upstream part of energy and carbon footprint of fuel production. As far as the operation phase is concerned, only carbon dioxide emissions for the GWP are considered; these have been calculated from the fuel consumption data provided by VEHLIB (Electric Hybrid Vehicle Library) (Vinot et al., 2008a; Jeanneret et al., 1999). To ensure system homogeneity, the GWP and energy consumption tied to fuel production are added in and originate from the same source as the ECORCE M software.

\subsection{Sloop methodology steps}

The Sloop methodology steps are listed in Figure 3. Its core is a single-criterion optimization process. The following sections will detail the methodology in terms of energy minimization. The GWP minimization process is similar although not expressly developed herein. 


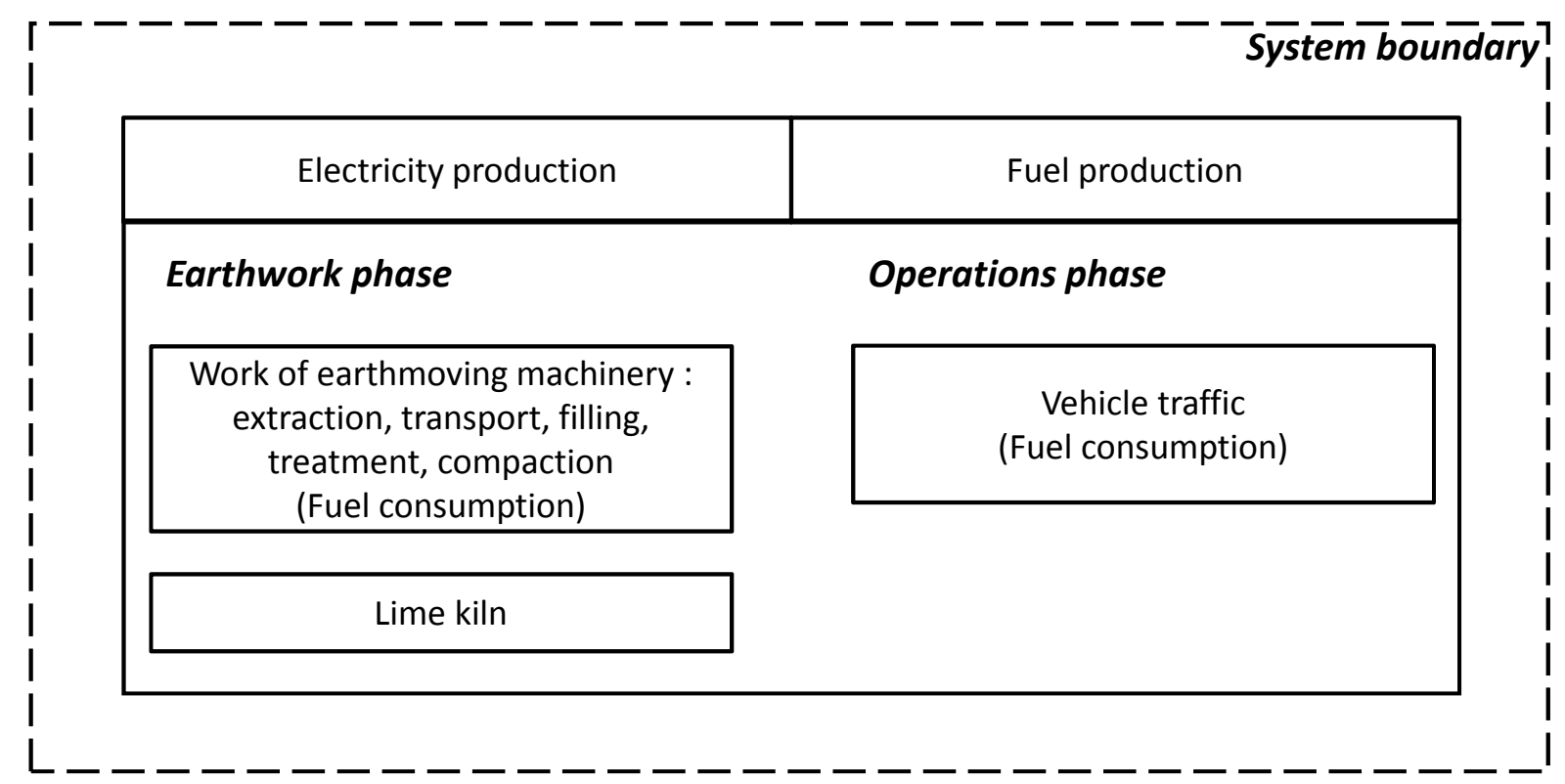

Figure 2. System boundaries

For a given initial longitudinal profile, the earthmoving volume is computed from the original ground level (included in the Worksite Data box). From this volume, an assessment of primary energy costs for the construction phase can be calculated. Next, vehicle trajectories are simulated on this initial longitudinal road profile, and primary energy consumption for the entire operations phase is estimated. The global cost in energy is the sum of construction cost and operating cost. The first iteration of the optimization algorithm analyzes these costs by computing longitudinal profile slopes and then proposes a new longitudinal profile. The optimization cycle can thus continue until convergence on the optimized profile, i.e. the one minimizing energy demand. An assessment of both the construction and operation phases will be provided in the next two sections.

\section{Construction phase Assessment}

\subsection{Hypothesis and assessment method}

For every road infrastructure project, the designer proposes a longitudinal profile that takes into account the following:

- design rules based on safety considerations, more specifically sight distance and braking distance depending on the pavement skid resistance;

- quality of the natural soil for possible reuse as embankment instead of final deposit. In case of reuse, specific treatments may be necessary (e.g. by incorporating lime into the soil);

- equilibrium between cut and fill in order to minimize earthworks. 


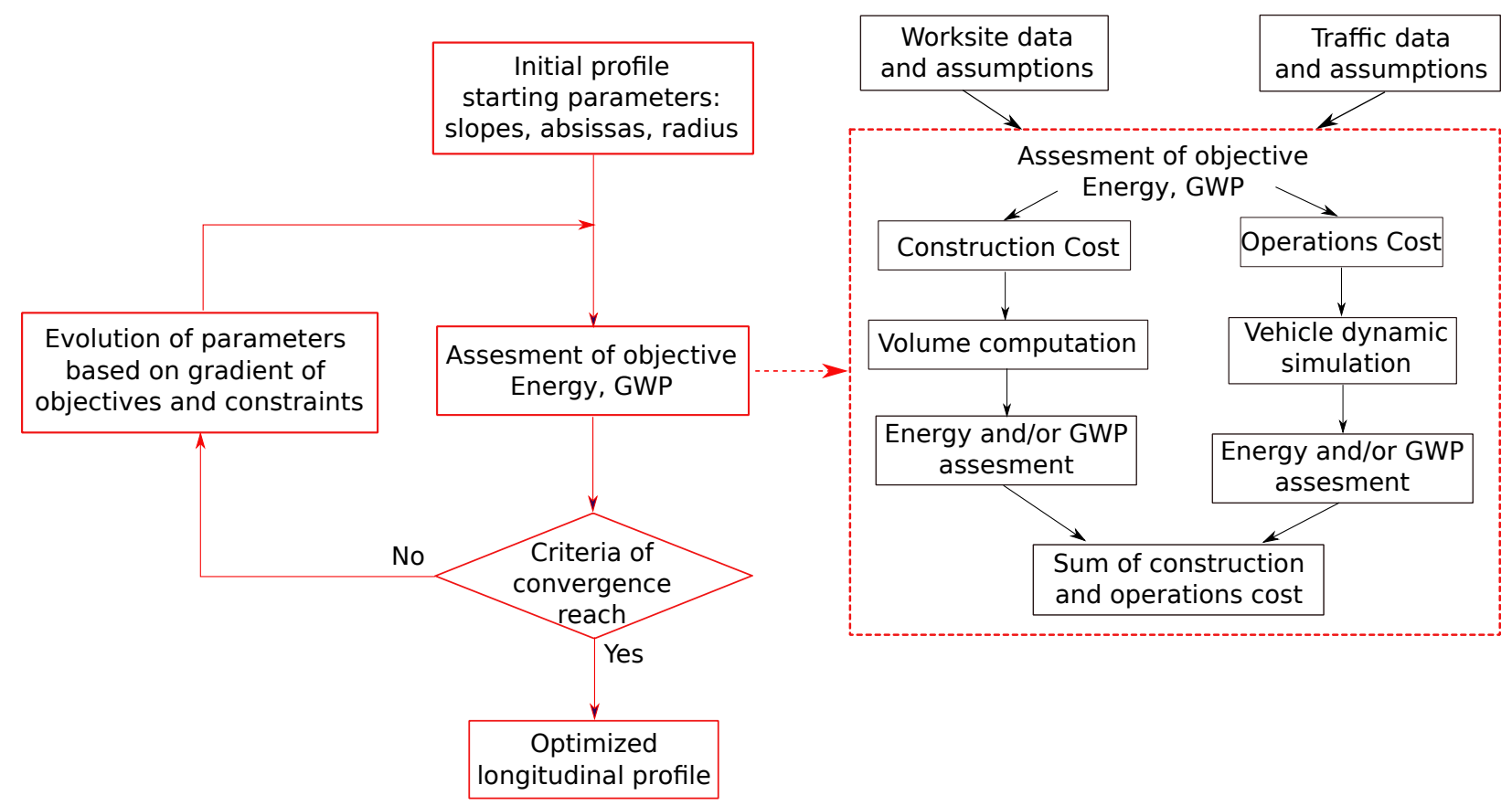

Figure 3. Slope Optimization (Sloop) Methodology

Starting from this longitudinal profile, considered as the reference profile, a 3D model of the road sub-grade, which supports the pavement layers, is computed. The comparison between this reference profile and the natural soil requires an accurate assessment of earthmoving. Various longitudinal profiles therefore lead to significant differences in earthmoving quantities. At the same time, these longitudinal road profiles do not imply significant changes in the pavement layer size because their widths and lengths mainly depend on traffic levels. Consequently, road pavement layers have not been formalized in the optimization process. Earthworks can be broken down into the following operations: raw material extraction, transportation and deposit as fill (in the case of reuse) or storage as final deposit (Capony et al. 2013). Any assessment of earthmoving quantities must therefore include an estimate of the fuel consumed by earthworks equipment (bulldozer, scraper, dump truck) during each task. Soil treatment needs to be quantified as well. These aspects are incorporated into the evaluation of energy consumption and GHG for the optimization process. To achieve this goal, earth movements are estimated from volume differences between the natural ground level and the current longitudinal profile The energy consumption and GHG emissions assessment is performed using the software ECORCE M, which features an extensive database pertaining to earthworks equipment (Capony et al. 2013; Jullien et al. 2015b).

\subsection{Volume Computation}

The longitudinal profile of the project, denoted Ps, and the natural soil profile, Pn, are altitudes relative to the distance $\mathrm{x}$ (also called the metric point); they are discretized every d meters. For each point on these discretized profiles, an altitude differential is computed and then multiplied by the road infrastructure width, $\mathrm{w}_{\mathrm{ph}}$, to obtain a surface area measure. In turn, this surface area is multiplied by the segment length, d, to yield a volume. Embankments with a given transverse slope, 


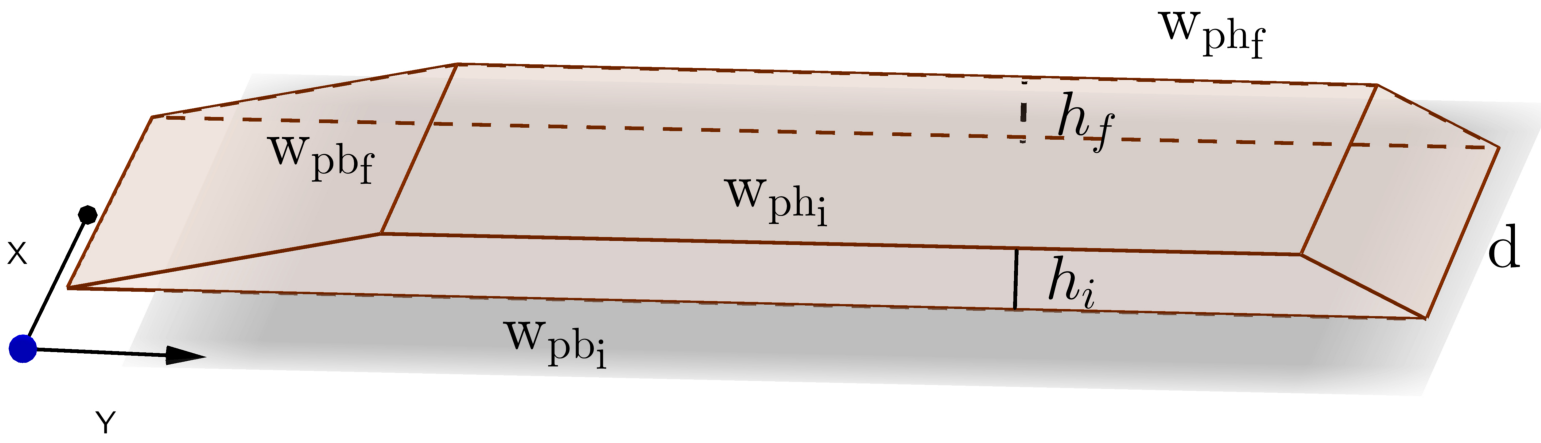

Figure 4. Elementary earthmoving Volume, $X$ is the longitudinal direction, $Y$ is the transverse direction

$\mathrm{s}_{\mathrm{b}}$, are added along each side of this volume as displayed in Figure 4. The embankment crosssection may be more complicated. For example, Figure 5 illustrates several of the embankment and trench road cross-sections considered in this study (Figure 4 corresponds to the first case). Cross-sections are chosen by the road designer according to mechanical considerations.

In conclusion, for each point on the discretized profiles, an elementary volume, $\mathrm{V}$, is computed. The relevant equations are presented in the Appendix A for the simplest embankment cross-section, as illustrated in Figure 4, though volume computations for all cases described in Figure 5 have been performed. Global embankment volume, $\mathrm{V}_{\mathrm{e}}$, and cut volume, $\mathrm{V}_{\mathrm{c}}$, are the sum of the elementary volumes, $\mathrm{V}$, along the discretized longitudinal profile.

\subsection{Assessment of energy consumption and GHG emissions from the Volume Computation}

With these calculated volumes, the environmental impacts can be assessed in terms of both energy consumption and GWP by taking into account raw material extraction, transportation between excavation and embankment, laying of materials, and quicklime treatment of natural soil. The energy consumption associated with the construction phase, denoted $\mathrm{E}_{\mathrm{c}}$, is calculated with the following equations:

$$
\begin{aligned}
& \mathrm{E}_{\mathrm{c}}=\mathrm{e}_{\mathrm{f}} \times \mathrm{V}_{\mathrm{e}}+\mathrm{e}_{\mathrm{cnu}} \times\left(\mathrm{V}_{\mathrm{c}}-\mathrm{V}_{\mathrm{e}}\right) \text { if } \mathrm{V}_{\mathrm{c}} \geq \mathrm{V}_{\mathrm{e}} \\
& \mathrm{E}_{\mathrm{c}}=\mathrm{e}_{\mathrm{f}} \times \mathrm{V}_{\mathrm{e}}+\mathrm{E}_{\text {AddMat }} \text { if } \mathrm{V}_{\mathrm{c}}<\mathrm{V}_{\mathrm{e}}
\end{aligned}
$$

with $e_{f}$ and $e_{c n u}$, being the energy consumption per cubic meter for the embankment and the cutting spread on the final deposit, respectively.

$$
\mathrm{e}_{\mathrm{f}}=\mathrm{e}_{\text {extrac }}+\mathrm{e}_{\text {trans }} \times \text { Dist }_{\mathrm{FC}}+\mathrm{e}_{\mathrm{spread}}+\mathrm{e}_{\text {lime }} \times \mathrm{r}_{\text {limeF }}
$$

$e_{\text {extrac }}$ is the energy consumed per cubic meter to extract the materials. $e_{\text {trans }}$ is the energy consumed to transport one cubic meter of materials over one kilometer. Dist $\mathrm{FC}_{\text {is }}$ the average distance between cut and fill; this parameter depends on the site configuration. $\mathrm{e}_{\text {spread }}$ is the energy consumed to spread one cubic meter of materials. $e_{\text {lime }}$ is the energy consumption associated with one cubic meter of quicklime. Lastly, $\mathrm{r}_{\text {limeF }}$ is the quicklime rate of the treated embankment materials. 

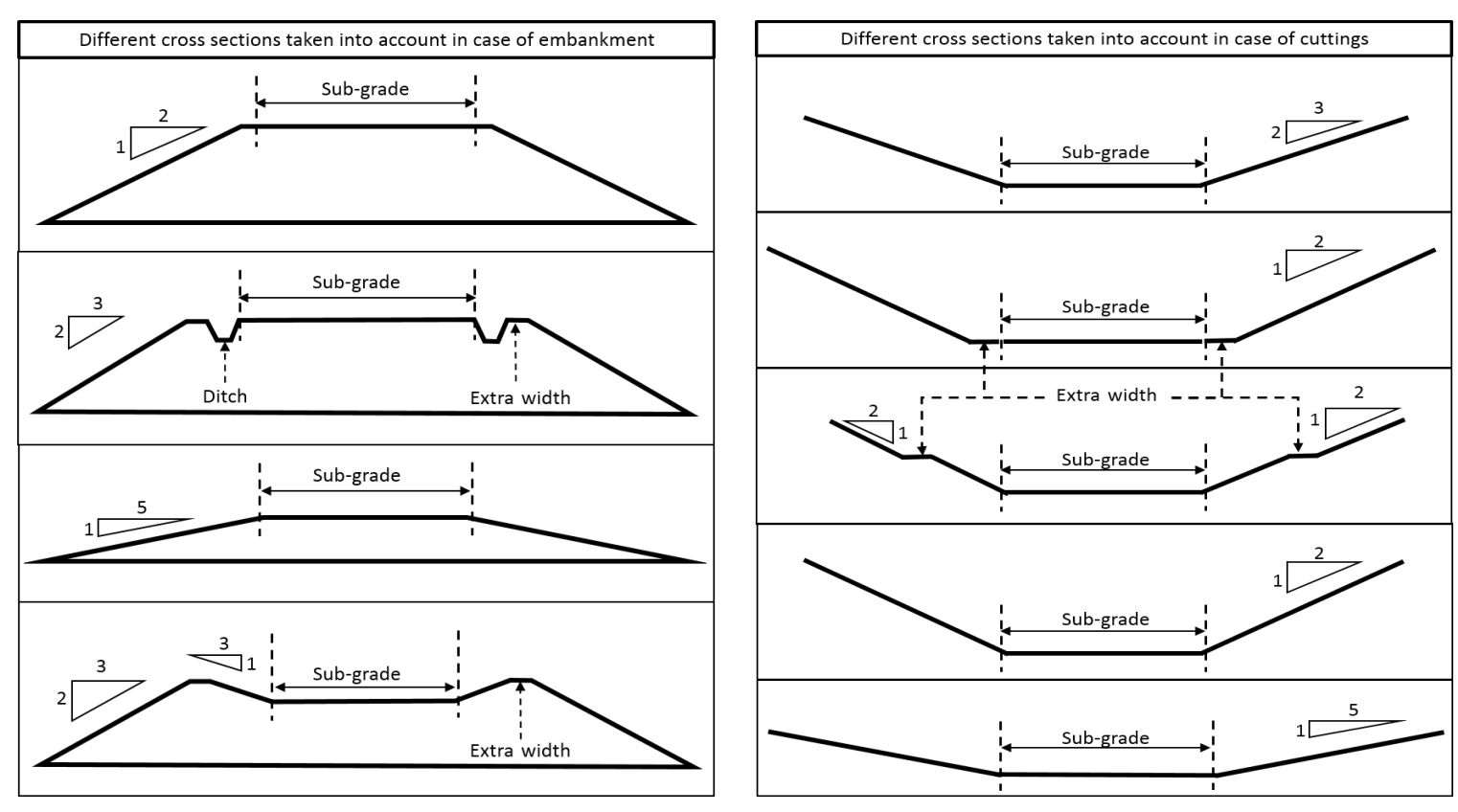

Figure 5. Cross-sections of the embankment and trench road

$$
\mathrm{e}_{\mathrm{cnu}}=\mathrm{e}_{\text {extrac }}+\mathrm{e}_{\text {trans }} \times \text { Dist }_{\mathrm{D}}+\mathrm{e}_{\text {spread }}+\mathrm{e}_{\text {lime }} \times \mathrm{r}_{\text {limeC }}
$$

with $r_{\text {limeC }}$ being the quicklime rate of treated materials stored in the final deposit. Dist $t_{D}$ is the average distance between cut and final deposit.

$\mathrm{E}_{\text {AddMat }}$ is the energy consumption due to required additional material in the event of a negative balance between fills and cuts (i.e. for a worksite with a materials deficit).

As far as GWP is concerned, the equations are set up similarly, i.e.:

$$
\begin{aligned}
& \mathrm{GWP}_{\mathrm{c}}=\operatorname{gwp}_{\mathrm{f}} \times \mathrm{V}_{\mathrm{e}}+\operatorname{gwp}_{\mathrm{cnu}} \times\left(\mathrm{V}_{\mathrm{c}}-\mathrm{V}_{\mathrm{e}}\right) \text { if } \mathrm{V}_{\mathrm{c}} \geq \mathrm{V}_{\mathrm{e}} \\
& \mathrm{GWP}_{\mathrm{c}}=\operatorname{gwp}_{\mathrm{f}} \times \mathrm{V}_{\mathrm{e}}+\mathrm{GWP}_{\text {AddMat }} \text { if } \mathrm{V}_{\mathrm{c}}<\mathrm{V}_{\mathrm{e}}
\end{aligned}
$$

with $\operatorname{gwp}_{\mathrm{f}}$ and $\mathrm{gwp}_{\mathrm{cnu}}$, being the GWP per cubic meter for the fill and the cutting spread in a final deposit, respectively. The breakdown of environmental impacts is the same as for energy consumption with a set of consistent notations:

$$
\begin{aligned}
& \operatorname{gwp}_{\mathrm{f}}=\mathrm{gwp}_{\text {extrac }}+\mathrm{gwp}_{\text {trans }} \times \text { Dist }_{\mathrm{FC}}+\mathrm{gwp}_{\text {spread }}+\mathrm{gwp}_{\text {lime }} \times \mathrm{r}_{\text {limeF }} \\
& \mathrm{gwp}_{\text {cnu }}=\mathrm{gwp}_{\text {extrac }}+\mathrm{gwp}_{\text {trans }} \times \mathrm{Dist}_{\mathrm{D}}+\mathrm{gwp}_{\text {spread }}+\mathrm{gwp}_{\text {lime }} \times \mathrm{r}_{\text {limeC }}
\end{aligned}
$$

The optimization process includes $\mathrm{E}_{\mathrm{c}}$ and $\mathrm{GWP}_{\mathrm{c}}$ as cost components to be minimized.

\section{Operation phase Assessment}

\subsection{Hypothesis and assessment method}

The operation phase is assessed by considering a functional unit composed of a road section with various longitudinal profiles and traffic levels summed over a reference period. Environmental 
impact indicators are calculated by modeling traffic flows for ten years. A number of assumptions must be adopted regarding both the composition and evolution of traffic. A distribution of vehicles across several categories has been considered with the assignment of an average vehicle in each category for purposes of numerical simulations. Moreover, the evolution in the vehicle distribution is based on a French national study (CCFA 2017). The energy and GWP indicators are calculated via total fuel consumption over a ten-year traffic period. Special attention has been paid to the choice of vehicle fuel consumption model. Both gasoline and diesel engines have been considered in the simulations with various conversion factors. Lastly, total fuel consumption is calculated separately in both directions in order to consider the impact of the longitudinal profile, which does not have the same effect depending on travel direction (ramps and downhills).

\subsection{Modeling considerations}

\subsubsection{Traffic}

Traffic is modeled using different classes of vehicles from passenger cars to heavy vehicles. The number of vehicles in each class has been obtained through traffic flow measurements. The following classes are proposed in the present work:

\section{Car: passenger cars;}

Van: van with a Gross Combination Weight Rating (GCWR) less than 3.5 tons;

Mini-truck: Vans with a Gross Combination Weight Rating (GCWR) greater than 3.5 tons;

Truck: 2-rigid-axle heavy vehicles with a Gross Combination Weight Rating (GCWR) below 19 tons;

Articulated vehicle: 5-axle heavy vehicles with a Gross Combination Weight Rating (GCWR) of up to 44 tons (fully loaded). This type of vehicle however is not running fully loaded all the time. In fact, trucks can sometimes travel with a partial load and even if full, depending on the type of goods, the maximum available load might not be reached. To take into account these different load scenarios, this class has been separated into two sub-classes: 40-tons for almost fully loaded, and 25-tons for half-loaded vehicles. This choice is based on weight-in-motion data analyses carried out on the French national road network.

The vehicle sub-classes can also be defined by engine type. For passenger cars, both diesel and gasoline engines are considered, whereas for all other categories, only diesel engines are assumed. For each class, a vehicle model has been parameterized to be representative of the average fuel consumption of the entire fleet. The technical characteristics of these classes and the composition of traffic are presented in Table 5. The vehicle speed is either the maximum legal speed or the maximum achievable speed, which means that vehicle speed actually depends on slope. For example, the truck speed may lie below the legal speed when traveling uphill and at the legal speed on downhill stretches, in using the engine brake and/or brake. 


\subsubsection{Vehicles}

Several fuel consumption models are available in the literature. As an example, Hammarström et al. (2012) proposed a semi-analytical consumption model taking into account vehicle speed, rolling resistance force and geometric characteristics (transverse and longitudinal profiles). The objective therein was to estimate fuel consumption over an entire road network. The model is thus set at the macro scale and focuses on rolling resistance. The influence of longitudinal road slope is not fully analyzed. A parameter introduced, called RF (for Rise and Fall), serves to measure the total increase and total decrease in altitude (per distance traveled). This parameter can be viewed as an "absolute variation" of a function that describes the mathematical nature of this concept. Moreover, the model has been calibrated for just three types of vehicles: car, truck, and articulated vehicle.

It was decided in this study to use a customized model called VEHLIB (Vinot et al. 2008a; Jeanneret et al. 1999), which is a Matlab/Simulink library developed at Ifsttar/LTE (Environment and Transportation Laboratory) to simulate all types of vehicles (from cars to articulated vehicles) and power-train architectures (from conventional to complex hybrid power-trains). It uses a modular cybernetic approach that allows for an easy exchange of vehicle components. According to this model, the vehicle is thus considered as a set of sub-systems. Modeling the vehicle therefore entails modeling its various units and the interactions taking place between them (Vinot et al. 2008b). Simulating a vehicle requires defining a driving cycle, represented by a vehicle speed as a function of time and an altitude as a function of distance profile. Both the normalized cycles, e.g. NEDC (New European Driving Cycle) or WLTP (Worldwide harmonized Light vehicle Test Procedure), and a personally defined cycle can be used in this application. The VEHLIB model is mainly composed of the engine, clutch, gear-box, final gear and vehicle chassis sub-model. The vehicle chassis model comprises an aerodynamic model and a rolling resistance model. The fundamental dynamic principle is solved in order to proceed upstream from wheel effort to engine solicitation.

Figure 6 displays the general principles of the fuel consumption computation. Starting from the trajectory of the vehicle and the longitudinal profile, Vehlib simulates the vehicle. One simulation output is the fuel consumption. Direct calculations yield the primary energy consumption and the $\mathrm{CO}_{2}$ emissions which is converted in GWP. In the following, the calculations for each step are presented.

Firstly, Newton's second law is applied to a vehicle described as a single degree of freedom model (see the car on Figure 6) in order to compute the tractive force $F_{t}$ developed by the wheels:

$$
\mathrm{m} \times \gamma=\mathrm{F}_{\mathrm{t}}-\mathrm{F}_{\mathrm{r}}
$$

where $m$ is the vehicle's mass and $\gamma$ is its acceleration. $F_{r}$ is the running resistance and is expressed as:

$$
\mathrm{F}_{\mathrm{r}}=\frac{1}{2} \rho S C_{x} \mathrm{v}^{2}+\mathrm{m} g\left(C_{r r 0}+C_{r r 1} \mathrm{v}\right)+\mathrm{m} g \sin \left(\alpha_{r}\right)
$$

Where $\rho$ is the air density, $S$ is the front vehicle area, $C_{x}$ is the drag forces coefficient, $C_{r r 0}$ et $C_{r r 1}$ are the tires rolling resistance coefficients, $g$ is the acceleration of gravity and $\alpha_{r}$ is the angle of the slope in radian. This quantity varies according to the profile.

As illustrated by the gears on Figure 6, knowing $F_{t}$ and v, the engine torque and angular speed 


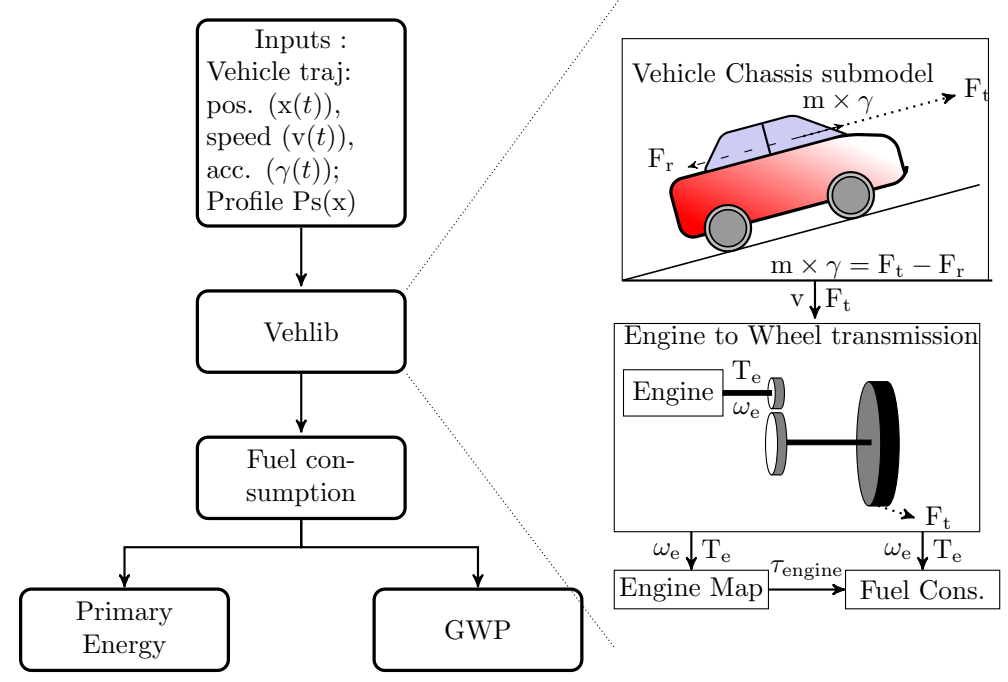

Figure 6. Fuel consumption computation

$\left(\mathrm{T}_{\mathrm{e}}\right.$ and $\left.\omega_{\mathrm{e}}\right)$ are then computed. We exhibit the equations only for the engine torque, equations for the angular speed are symmetric.

Knowing $\mathrm{F}_{\mathrm{t}}$, the torque $T_{w}$ to be applied to the wheel is then:

$$
T_{w}=\mathrm{F}_{\mathrm{t}} \times R_{w}
$$

where $R_{w}$ is the wheel radius.

Going upstream to the engine shaft considering the different gear ratios, the engine torque $T_{e}$ is then:

$$
\mathrm{T}_{\mathrm{e}}=T_{w} \frac{k_{f g} \cdot k_{g b}}{\eta_{f g} \cdot \eta_{g b}} \quad \text { if } T_{w}>0
$$

where $k_{f g}$ and $\eta_{f g}$ are the gear ratio and efficiency of the final gear, $k_{g b}$ and $\eta_{g b}$ are the gear ratio and efficiency of the gear box.

Fuel consumption is then calculated using specific fuel consumption maps (e.g. see Figure 7 for a 390kW diesel engine). VEHLIB has been validated with experimental data. For example, the map of the vehicle representing the truck class (2-rigid-axle heavy vehicle) (Figure 7) was calibrated with experimental measurements recorded by CEREMA-Lyon (France's National Center For Studies and Expertise on Risks, Environment, Mobility, and Urban and Regional Planning).

Lastly, the fuel consumption of the different type of vehicles (see section 4.2.1) are calculated in the two directions of circulation and summed to obtain fuel consumption due to the traffic for $N_{\text {years }}$ years (here, $N_{\text {years }}=10$ ). Knowing these quantities, the computation of both criteria GWP and primary energy is straightforward taking into account the boundaries of the LCA system which includes fuel production and supply (see Figure 2). We present the equations for the GWP 
Table 1. Values of the emission factors

\begin{tabular}{lrr}
\hline & Diesel & Gasoline \\
\hline eqCO 2 in kg/l & $\tau_{\mathrm{d} 2 \mathrm{GWP}}=2.98$ & $\tau_{\mathrm{g} 2 \mathrm{GWP}}=2.66$ \\
Primary energy in $\mathrm{MJ} / 1$ & $\tau_{\mathrm{d} 2 \text { Energy }}=38.3$ & $\tau_{\mathrm{g} 2 \text { Energy }}=34.1$ \\
\hline
\end{tabular}

during the operation phase, $\mathrm{GWP}_{\mathrm{o}}$, since the equations for the primary energy are identical for their structure.

$$
\mathrm{GWP}_{\mathrm{o}}=\sum_{k=1}^{N_{\text {years }}} \sum_{\text {veh }} N_{\text {vehk }}\left(\frac{F C_{d 1}+F C_{d 2}}{2}\right) \tau_{\mathrm{FC} 2 \mathrm{GWP}}
$$

where $N_{\text {years }}$ is the number of years considered in the study, $N_{\text {vehk }}$ is the numbers of each type of vehicles composing the traffic for the year $k$ (see section 4.2.1), $F C_{d 1}$ and $F C_{d 2}$ are the fuel consumption in each directions, and $\tau_{\mathrm{FC} 2 \mathrm{GWP}}$ is the emission factor of one liter of fuel (its value is $\tau_{\mathrm{d} 2 \mathrm{GWP}}$ for diesel and $\tau_{\mathrm{g} 2 \mathrm{GWP}}$ for gasoline).

The emission factor coefficient is calculated adding the GWP of combustion and those by the fuel production part. For the combustion, it is derived from the combustion equation of a reference fuel in stoichiometric conditions:

$$
\mathrm{CH}_{1.86}+1.4625 \mathrm{O}_{2}->\mathrm{CO}_{2}+0.925 \mathrm{H}_{2} \mathrm{O}
$$

where $\mathrm{CH}_{1.86}$ is a hydrocarbon with a ratio hydrogen - carbon of 1.86 for diesel (respectively 1.89 for gasoline) according to the European norm (EU 2010). For the fuel production and supply part the emission factor comes from ECORCE M software (Jullien et al. 2015b). Table 1 summarizes the aggregate emission factors used in equation 13 for diesel and gasoline and for GWP and primary energy with consistent notations, described in Appendix B.

For the sake of clarity, we presented simplified equations. The simulation has to take into account some particular cases which complicate them. For example, going downhill if the slope is too steep, running resistance becomes a driving force in particular for trucks, and the equations are then modified to take into account the braking system (engine brake and mechanical brake). When going uphill, the engine limitations imply that the actual speed may be lower than the legal speed. This fact is simulated by Vehlib. Technical equations are moreover added for the choice of gear ratio.

\section{Optimization method}

Previous sections have described the energy consumption or Global Warming Potential (GWP) assessment of both the construction and operations phases of a road project according to the longitudinal road profile. This section will present the method implemented to identify the longitudinal profile that globally optimizes a criterion $\mathrm{J}$, which designates either the primary energy consumption E or the GWP of a road project. J depends on the longitudinal profile Ps, i.e.:

$$
\mathrm{J}(\mathrm{Ps})=\mathrm{J}_{\mathrm{c}}(\mathrm{Ps})+\mathrm{J}_{\mathrm{o}}(\mathrm{Ps})
$$




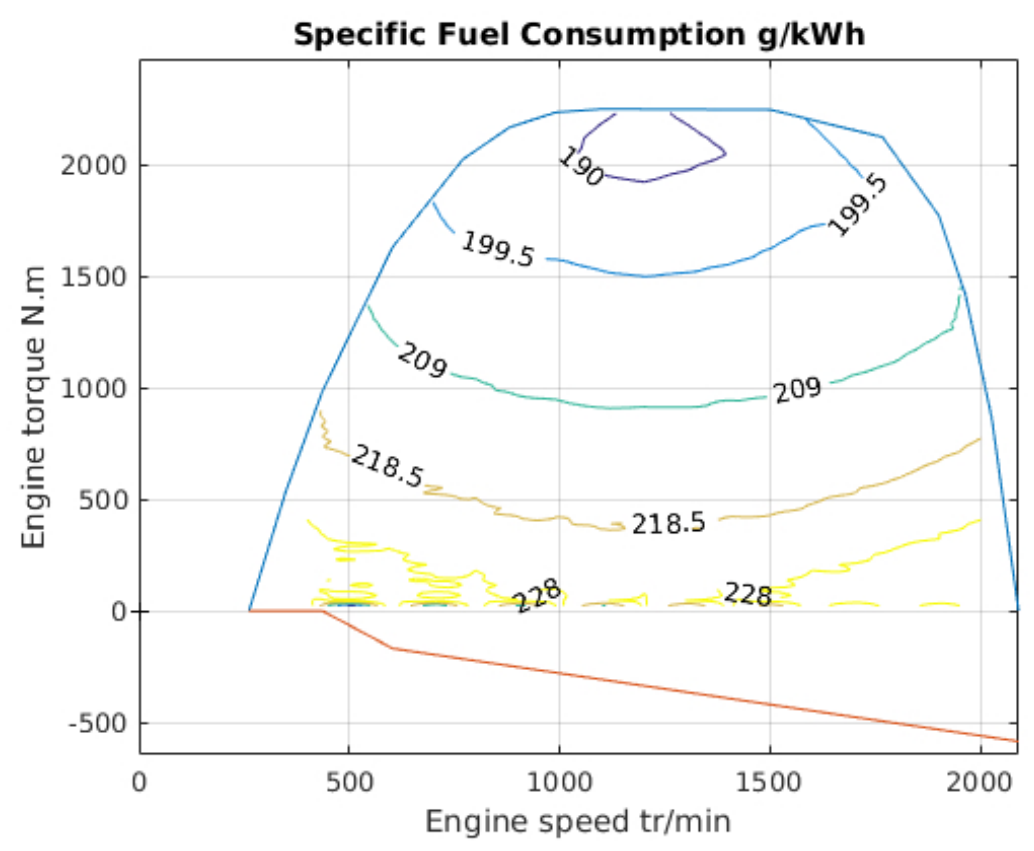

Figure 7. Specific fuel consumption maps of a diesel engine

with $\mathrm{J}_{\mathrm{c}}(\mathrm{Ps})$ being the energy consumed during construction phase, and $\mathrm{J}_{\mathrm{o}}(\mathrm{Ps})$ the energy consumed during the operations phase. $\operatorname{Ps}(\mathrm{x})$ is the height of the longitudinal profile as a function of the distance, $\mathrm{x}$. Ps maps $\left[\mathrm{x}_{o}, \mathrm{x}_{f}\right]$ to $\mathbb{R}$ where $\mathrm{x}_{o}$ is the metric point at the beginning of the project (original point) and $\mathrm{x}_{f}$ the metric point at the end of the project (final point). This function must to be linked with the existing road, which implies that the road altitudes at the beginning and end of the project are constrained: $\operatorname{Ps}\left(\mathrm{x}_{o}\right)=\mathrm{Ps}_{o} ; \operatorname{Ps}\left(\mathrm{x}_{f}\right)=\mathrm{Ps}_{f}$. The optimization problem can then be defined as follows:

$$
\begin{gathered}
\min _{\mathrm{Ps}} \mathrm{J}(\mathrm{Ps}) \\
\text { subject to } \mathrm{Ps}\left(\mathrm{x}_{o}\right)=\mathrm{Ps}_{o}, \operatorname{Ps}\left(\mathrm{x}_{f}\right)=\mathrm{Ps}_{f},
\end{gathered}
$$

Since the optimal solution is a function, this problem becomes one of infinite-dimensional optimization. In this form, the solution to this optimization process cannot be directly applied by road designers. To overcome this obstacle, the longitudinal profile of a road is modeled as a sequence of straight lines linked by circular arcs. This sequence must follow stringent rules, as dictated by technical standards: such standards are specified in national guidelines, e.g. AASHTO (1994) for the United States or Setra (2000) for France. Moreover, infinite-dimensional optimization problems are difficult to solve.

For all these reasons, the previous infinite-dimensional optimization has been simplified into a finite-dimensional problem. The function Ps is parameterized as illustrated in Figure 8 and described by the following set of typical equations for road designers: 


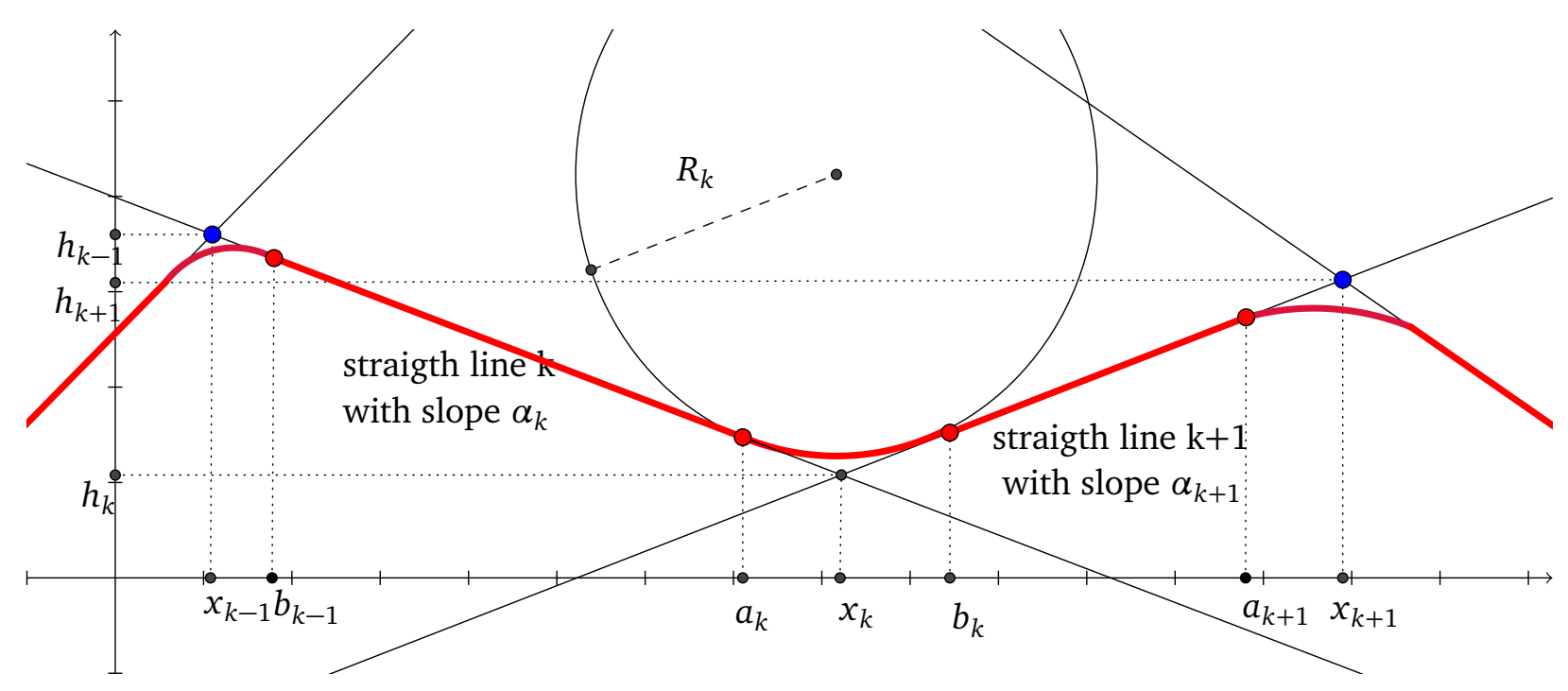

Figure 8. Longitudinal profile (in red) modeled as a sequence of straight lines linked by circular arcs

$$
\begin{array}{lr}
\operatorname{Ps}(x)= & \alpha_{k}\left(x-x_{k}\right)+h_{k} \text { if } b_{k-1} \leq x<a_{k} \\
\operatorname{Ps}(x)= & C_{x_{k}, h_{k}, \alpha_{k}, R_{k}, x_{k+1}, h_{k+1}, \alpha_{k+1}}(x) \text { if } a_{k} \leq x<b_{k} \\
\operatorname{Ps}(x)= & -\alpha_{k+1}\left(x_{k+1}-x\right)+h_{k+1} \text { if } b_{k} \leq x<a_{k+1}
\end{array}
$$

$\alpha_{k}$ is the longitudinal slope of the straight line $k, x_{k}, h_{k}$ are the abscissa and altitude of the point of the intersection of straight line $k$ and straight line $k+1 . b_{k-1}$ and $a_{k}$ are internal variables output from the computation of the circle linking this straight line $k$ to the next straight line.

$C_{x_{k}, h_{k}, \alpha_{k}, R_{k}, x_{k+1}, h_{k+1}, \alpha_{k+1}}(x)$ is the equation of the circle, with radius $R_{k}$, that links straight line $k$ to straight line $k+1$. This circle is tangent to straight line $k$ at the point with abscissa $a_{k}$ and is tangent to the straight line $k+1$ at the point with abscissa $b_{k}$. With these equations, the derivative of $\operatorname{Ps}(x)$ is continuous which is a mandatory condition to simulating vehicle dynamics models. Also, circular arcs are often used by road designers to "smooth" the profile. For this purpose, large radii $\left(R_{k}>10,000 \mathrm{~m}\right)$ are chosen, thus implying that the circular arcs cannot be neglected in the longitudinal profile model.

The boundary conditions, i.e. the connection with the existing road, are managed by setting: $x_{0}=x_{b}, \alpha_{0}=\alpha_{b}, \operatorname{Ps}\left(\mathrm{x}_{0}\right)=\mathrm{Ps}_{b}, x_{n}=x_{e}, \alpha_{n+1}=\alpha_{e}, x_{n}=x_{e}, \operatorname{Ps}\left(\mathrm{x}_{n}\right)=\operatorname{Ps}_{e} . \alpha_{b}$ is the longitudinal slope of the existing road before $x_{b}$, which is the beginning of the studied profile, $\alpha_{e}$ is the longitudinal slope of the existing road after $x_{e}$, which is the end of the studied profile.

The degrees of freedom in this parameterization are: $x_{k}, \alpha_{k}, R_{k}$, with $k$ varying from 1 to $n-1$ and $R_{0}, R_{n}, \alpha_{n}$.

The other variables can be obtained from the degrees of freedom. $h_{k}$ is computed in knowing $x_{k-1}, x_{k}$ and $\alpha_{k} . a_{k}, b_{k}$ are computed in knowing the equation of circle $C\left(x_{k}, h_{k}, \alpha_{k}, R_{k}, x_{k+1}, h_{k+1}, \alpha_{k+1}\right)$.

With this parametrization, infinite-dimensional optimization problem (Equation 16) becomes 
the following finite-dimensional problem.

$$
\begin{aligned}
& \underset{x_{k}, \alpha_{k}, R_{k}, k=1 \ldots n-1 R_{0} R_{n} \alpha_{n}}{\operatorname{minimize}} \\
& \text { subject to } \operatorname{Ps}\left(\mathrm{x}_{o}\right)=\mathrm{Ps}_{o}, \operatorname{Ps}\left(\mathrm{x}_{f}\right)=\operatorname{Ps}_{f}
\end{aligned}
$$

Since the chosen parameterization is commonplace for road designers, the initial profile, $\mathrm{Ps}_{0}$, is the longitudinal profile designed by them. One parameter of the optimization program $n$, i.e. the number of straight lines, is given by the road designers in order to adjust the profile to the natural soil. Its value is typically set by the initial profile. The degrees of freedom of the optimization program: $x_{k}, \alpha_{k}, R_{k}$ are not completely independent of one another. For example, if the consecutive straight lines are parallel (i.e $\alpha_{k+1}=\alpha_{k}$ ), it is impossible to build a circular arc that joins them. Another constraint is that the beginning of the circular arc $d_{k}$ must lie after $x_{k}$. Moreover, the assumptions of the methodology implies that the profile cannot be completely different from the initial profile. It means that the variations of the degrees of freedom are bounded. In summary, different technical constraints are added to the optimization protocol (Equation 18).

\section{Application}

In this section, the Sloop methodology is applied to a French road project in order to demonstrate its efficiency in defining a longitudinal profile that minimizes primary energy consumption or GWP. This road project had been carried out prior to our study. The actual road and alternative profiles delivered by Sloop are compared. Since the road actually exists, real traffic measurements have been performed to verify traffic estimations and recalibrate them as needed.

\subsection{Description of the case study}

The section is a $4.75 \mathrm{~km}$ long $2 \times 2$ lane road in the French national road network; its longitudinal slope varies from $-2 \%$ to $2 \%$. The same asphalt pavement mix has been laid over the whole section. All the technical data (earthworks, pavement structure) required to assess the energy demand and GWP during construction works were collected from the relevant road authorities.

\subsection{Construction phase Parameters}

During the construction phase, the energy consumption required and GHG emissions produced due to the tasks of extraction, spreading, transportation and treatment are described according to Equation. 1, 2, 5 and 6.

The calculations require identifying a number of parameters specific to this site. These values are: average distance between cut and fill $\left(\right.$ Dist $_{\mathrm{FC}}=1.132 \mathrm{~km}$ ), average distance between cut and final deposit $\left(\right.$ Dist $_{\mathrm{D}}=0.869 \mathrm{~km}$ ), average quicklime rate of the material treated for fill $\left(\mathrm{r}_{\text {limeF }}=1.04 \%\right)$ and the quicklime rate for the final deposit, set at $0 \%$ given the absence of treatment $\left(\mathrm{r}_{\text {limeC }}=0 \%\right)$. This site features highly accurate values from dedicated experiments carried out in 2012 as part of the national TERDOUEST project (funded by the French National Research Agency). At most worksites, these parameters can be identified from mass diagrams. This particular site had a material surplus; for this reason, the parameters $\mathrm{E}_{\text {AddMat }}$ and $\mathrm{GWP}_{\text {AddMat }}$ are not used herein. Had such not been the case, then these parameters would be provided by life 
Table 2. Values of the parameters used to assess the construction phase

\begin{tabular}{llrlr}
\hline \multicolumn{1}{c}{ Tasks } & Energy label & Value $\left(\mathrm{MJ} / \mathrm{m}^{3}\right)$ & GWP label & Value $\left(\mathrm{kgeqCO}_{2} / \mathrm{m} 3\right)$ \\
\hline Extract & $\mathrm{e}_{\text {extrac }}$ & 9.6 & $\mathrm{gwp}_{\text {extrac }}$ & 0.753 \\
For $1 \mathrm{~km}$ of transportation & $\mathrm{e}_{\text {trans }}$ & 15.4 & $\mathrm{gwp}_{\text {trans }}$ & 1.235 \\
Spread & $\mathrm{e}_{\text {spread }}$ & 11.6 & $\mathrm{gwp}_{\text {spread }}$ & 0.913 \\
Quicklime & $\mathrm{e}_{\text {lime }}$ & 9000 & $\mathrm{gwp}_{\text {lime }}$ & 2196 \\
\hline
\end{tabular}

Table 3. Measured traffic for the different vehicle categories ( $\mathrm{t}$ : metric ton)

\begin{tabular}{lrrr}
\hline \multicolumn{1}{c}{ Vehicle class } & $\begin{array}{c}\text { Traffic } \\
\text { (per day/per direction) }\end{array}$ & Distribution & $\begin{array}{c}\text { Actual average speed } \\
(\mathrm{km} / \mathrm{h})\end{array}$ \\
\hline Car & 2419 & $70 \%$ & 113 \\
Van $(<3.5 \mathrm{t})$ & 130 & $4 \%$ & 103 \\
mini-truck & 102 & $3 \%$ & 95 \\
Truck and articulated vehicle & 802 & $23 \%$ & 88 \\
\hline Total & 3453 & $100 \%$ & \\
\hline
\end{tabular}

cycle inventory databases. In addition, the values of energy consumption and GWP for each task, as extracted from the tool ECORCE M (Jullien et al. 2015b) during earthmoving are considered in this assessment (see Table 2).

\subsection{Simulation Parameters of the Operations phase}

\subsubsection{Traffic measurements}

Assumptions regarding traffic evolution heavily influence the impact indicator values. In 1998 (origin of this project), traffic was estimated at 8,800 vehicles/day with $23 \%$ heavy vehicles (i.e. the sum of mini-trucks, trucks and articulated vehicles - these classes have not been distinguished in this initial study), in both directions. Moreover, traffic growth was assumed to reach 12,820 vehicles/day by 2020. To verify the validity of these assumptions, traffic data were collected in 2016 by CEREMA Lyon over a two-week period. Two counting devices with radars were installed in order to record the number of vehicles and their type and speed in both directions (see Figure 9 for the location of these devices).

As an initial finding, the measurements showed that the level of traffic is equivalent in both directions, and it was decided to apply the same values for average daily traffic in the two directions.

Table 3 has been compiled from measured traffic by estimating an average daily traffic, which in both directions equals around 7,000 vehicles, while the road project hypothesis adopted in 1998 called for 8,800 vehicles/day, for an overestimation of approx. $20 \%$. Moreover, the proportion of heavy vehicles (>3.5 tons) is slightly higher, with $26 \%$ vs. $23 \%$ in the initial hypothesis.

Since this initial assumption on vehicle evolution was not consistent with measurements, we decided to consider a stable traffic in terms of evolution in the number of vehicles over 10 years. As regards traffic composition, we tracked the scenario of evolution in the French fleet, as defined by the French Ministry of Environment, Energy and Maritime Affairs (MEEM 2017). With these two 
Table 4. Evolution in the traffic assumption for the different vehicle categories (Proj means Projected, veh for vehicle)

\begin{tabular}{lccrr}
\hline \multicolumn{1}{c}{ Vehicle class } & Traffic 2016 & $\begin{array}{c}\text { Fuel and veh } \\
\text { subclass }\end{array}$ & $\begin{array}{c}\text { Projected } \\
\text { distribution } \\
\text { for 2016 }\end{array}$ & $\begin{array}{c}\text { Proj. Average } \\
\text { distribution } \\
2016 \text { to 2025 }\end{array}$ \\
\hline Car & 2419 & gasoline & 793 & 797 \\
Small van $<3.5 \mathrm{t}$ & & diesel & 1626 & 1618 \\
mini-truck & 130 & diesel & 130 & 134 \\
Truck and articulated veh. & 102 & diesel & 102 & 102 \\
& 802 & Diesel truck $<32 \mathrm{t}$ & 447 & 406 \\
Total & & Diesel articulated $<44 \mathrm{t}$ & 355 & 396 \\
\hline
\end{tabular}

assumptions, the total traffic volume for each vehicle class can be estimated over a 10-year period. Table 4 presents both the averaged measured traffic values and estimated traffic values. It is clear that this ten-year traffic volume estimation is rough and cannot be considered as an accurate traffic model. Nevertheless, the objective of our case study is to demonstrate the feasibility and interest of the given optimization method. Hence, this traffic model can be modified without having any consequence on the methodology. In road infrastructure projects, a very thorough traffic estimation is performed, and these data would be considered in the Sloop method.

\subsubsection{Vehicle simulation}

Traffic is divided into vehicle classes, and dynamic models are introduced to represent the vehicle behavior in each class. In France, diesel engines are installed in roughly $70 \%$ of all passengers cars, but nearly $100 \%$ in trucks and vans. Since the traffic composition on the test section remains quite similar to the overall French composition, it was decided to adopt the same assumption on the division of engine types. Moreover, the "diesel personal car" class has been split into three categories, modeled by a given vehicle type (small, medium and high), as available in VEHLIB. The data used to calibrate these models were derived from vehicles that had been tested and characterized with an Ifsttar chassis dynamometer, while the heavy vehicle characteristics entered into the models were provided by CEREMA Lyon. The number of vehicles in each class was then determined by means of the data obtained from CEREMA Lyon during the traffic measurement campaign. Table 5 lists the technical characteristics of the various vehicles used for this assessment, i.e.:

- number of vehicles passing in one day in one direction over the studied part of the road;

- mass of each type of vehicle (including load and passengers);

- product of the drag coefficient and the front surface area, denoted S.C.

- tire rolling resistance coefficients, in assuming a constant part $\left(C_{r r 0}\right)$ and a part proportional to vehicle speed $\left(C_{r r 1}\right)$. 
Table 5. Vehicle data (t: metric ton)

\begin{tabular}{crrrrr}
\hline classes & vehicles per day & $\begin{array}{r}\text { Mass } \\
(\mathrm{t})\end{array}$ & $\begin{array}{r}S . C_{x} \\
\left(\mathrm{~m}^{2}\right)\end{array}$ & $\begin{array}{r}C_{r r 0} \\
\left(1 \times 10^{-3}\right)\end{array}$ & $\begin{array}{r}C_{r r 1} \\
\left(\mathrm{~m}^{-1} s \times 10^{-6}\right)\end{array}$ \\
\hline & & & & & \\
articulated vehicle (40t) & 198 & 40 & 5.2 & 4.824 & 39.5 \\
articulated vehicle (25t) & 198 & 25 & 5.2 & 4.824 & 39.5 \\
truck (19t) & 406 & 19 & 3.27 & 4.824 & 39.5 \\
gasoline Car & 799 & 1.48 & 0.73 & 11.84 & 5.25 \\
small class diesel Car & 540 & 1.12 & 0.68 & 11.84 & 5.25 \\
medium class diesel Car & 540 & 1.23 & 0.97 & 11.84 & 5.25 \\
high class diesel Car & 540 & 1.51 & 0.82 & 11.84 & 5.25 \\
mini-truck & 102 & 3.69 & 3.18 & 11.84 & 5.25 \\
Van & 130 & 2.53 & 1.98 & 11.84 & 5.25 \\
\hline
\end{tabular}

\subsection{Optimized profiles}

The initial profile is the current one denoted $\mathrm{Ps}_{\text {actual }}(\mathrm{x})$; it is divided into six subsections $(n=6)$ and its length equals $4.75 \mathrm{~km}$ (see "Longitudinal profile optimization section" in Figure 9). The number of degrees of freedom is therefore 18, according to the formulation of the simplified optimization problem (see Equation 18), i.e.:

- 5 abscissas defining the intersection point between two consecutive straight lines;

- 6 slopes, one per section;

- 7 radii for the circle linking the section, since the two radii of the two extremities are also degrees of freedom.

A nonlinear constraint is applied to respect the final altitude $\left(\mathrm{Ps}_{f}\right)$ and in order to connect the optimized section with the existing road. Several technical constraints, based on guidelines and state-of-the-art, have been added to produce a consistent profile. The number of subsections is fixed, but the length and longitudinal slope of each subsection are free to be adjusted by the optimization algorithm. The simplified optimization problem (eq. 18) is solved using the Sequential Quadratic Programming (SQP) algorithm available in the "fmincon" Matlab Software function; it starts with the initial profile defined by $\mathrm{Ps}_{\text {actual }}(\mathrm{x})$.

Figure 9 exhibits the optimized profiles, the reference longitudinal profile and the natural terrain. The reference profile is that of the existing road $\left(\mathrm{Ps}_{\text {actual }}(\mathrm{x})\right)$. The reference profile is smoother than the natural soil profile. The large natural soil variations in altitude have indeed been lowered to build the road. The flat profile is unrealistic profile that it links the beginning and end points with a straight line. It provides the maximum potential gain during the operation phase.

Results of the optimization process indicate a $6 \%$ savings of the global primary energy (Table 6) compared to the existing profile. A $9 \%$ savings on GWP is also obtained. According to the criteria of primary energy and GWP impact, the optimized profiles are smoother and lower 


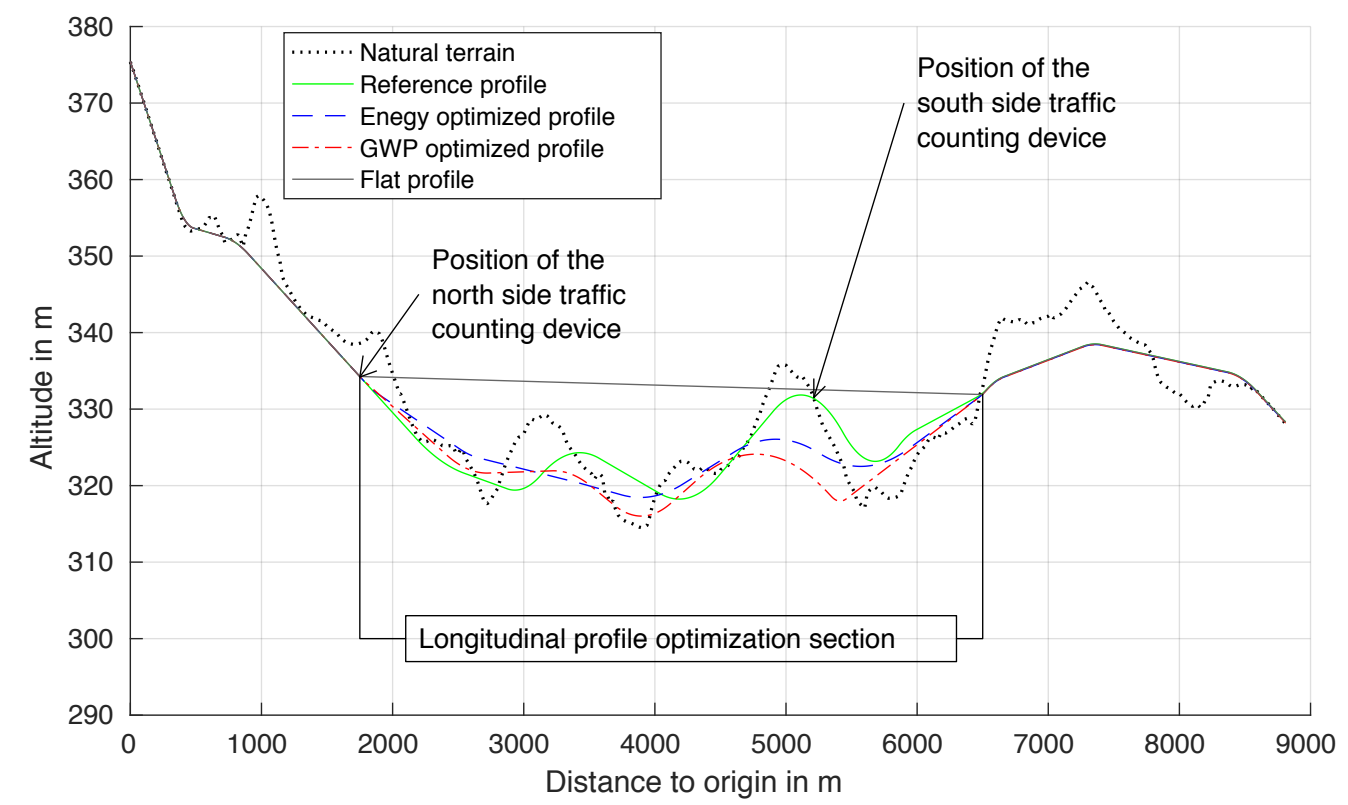

Figure 9. Optimized profiles vs. the initial (reference) profile

than the reference profile. The solution to the GWP optimization is the lowest profile. The reasons for these differences are detailed in the following section. Optimized profiles are however not completely different from the initial profile so that the assumptions of a local optimization described in section 2 are fulfilled (in particular, the maintenance phase is the same for the initial profile and the optimized profile).

\section{Discussion}

\subsection{Analysis of optimized solutions}

For starters, the energy savings and GWP gains are significant between the optimized longitudinal profiles and the reference profile. According to Table 6, these gains are equivalent to the energy consumption and GWP impact of the construction phase alone. An energy savings of 31 $\mathrm{TJ}$ (resp. 4129 teqCO $\mathrm{CO}_{2}$ for GWP) is achieved during both the operation (24 TJ) and construction (7 TJ) phases. In comparison, the primary energy consumption for the construction phase alone equals $35 \mathrm{TJ}$ (resp. 5950 teqCO $\mathrm{CO}_{2}$ for GWP), with respect to the reference profile, and this figure decreases to $28 \mathrm{TJ}$ (resp. 3422 teqCO $\mathrm{CO}_{2}$ for GWP) in the optimized profile. This finding means that by taking into account the future use of the road over 10 years, the cost of the construction phase in GWP or energy can be nearly offset by optimizing road slopes.

Secondly, an optimization procedure that takes both construction and operating costs into account is mandatory. The solution optimizing just the operating cost is obviously a flat profile between the beginning and end of the studied section (see Figure 9). According to Table 6, the 
Table 6. Overall results (TJ: Tera Joules, teqCO 2 : metric ton equivalent $\mathrm{CO}_{2}$ )

\begin{tabular}{|c|c|c|c|c|c|c|}
\hline & $\begin{array}{r}\text { Reference } \\
\text { profile }\end{array}$ & $\begin{array}{r}\text { Opt. profile } \\
\text { energy }\end{array}$ & $\begin{array}{l}\text { Gain } \\
\text { in \% }\end{array}$ & $\begin{array}{r}\text { Opt. profile } \\
\text { GWP }\end{array}$ & $\begin{array}{l}\text { Gain } \\
\text { in \% }\end{array}$ & $\begin{array}{r}\text { Flat } \\
\text { profile }\end{array}$ \\
\hline Primary energy use (TJ) & 497 & 472.6 & 5 & 477.5 & 4 & 470.9 \\
\hline Primary energy construction (TJ) & 34.9 & 28.1 & 19 & 32.1 & 8 & 267 \\
\hline Global primary energy (TJ) & 531.9 & 500.7 & 6 & 509.6 & 4 & 738 \\
\hline GWP use (teqCO $\left.\mathrm{CO}_{2}\right)$ & 38174 & 36291 & 5 & 36673 & 4 & 36165 \\
\hline GWP construction (teqCO $\mathrm{CO}_{2}$ ) & 5950 & 4382 & 26 & 3422 & 42 & 52443 \\
\hline Global GWP (teqCO $\left.{ }_{2}\right)$ & 44124 & 40673 & 8 & 40095 & 9 & 88611 \\
\hline
\end{tabular}

construction costs of this simple solution explode: $267 \mathrm{TJ}$ and 52,4433 teqCO $\mathrm{CO}_{2}$, in comparison with $35 \mathrm{TJ}$ and 5,950 for the reference profile. Its total costs (738 $\mathrm{TJ}$ and 88,6113 teqCO $\mathrm{C}_{2}$ ) significantly outweigh the total cost of our optimized solution (500 $\mathrm{TJ}$ and 40,0953 teqCO $\mathrm{CO}_{2}$ ). This profile also shows that compared to the reference profile, the gain during the operations phase can be evaluated at 26 TJ. Moreover, the energy-optimized profile is close to the minimum attainable profile (i.e. $472.6 \mathrm{TJ}$ vs. $470.9 \mathrm{TJ})$.

Thirdly, the gain in GWP is greater than in primary energy (9\% vs. $6 \%$ ). In targeting energy optimization, the gain is mainly generated by the operation phase ( $24 \mathrm{TJ}$ vs. $7 \mathrm{TJ}$ for construction). On the other hand, when optimizing with GWP as the objective, the gain is mainly due to the construction phase $\left(2,528\right.$ teqCO $\mathrm{CO}_{2}$ vs. 1,501 teqCO $\mathrm{CO}_{2}$ for the operation phase). Moreover, the energy-optimized profile differs slightly from the GWP-optimized profile (see Figure 9). These two facts are explained by the quicklime soil treatment, which is costly in terms of both energy and GWP. It has a higher relative GWP cost than a relative energy cost: in Table2, the parameter is 2200 $\mathrm{kgeqCO}_{2} / \mathrm{m} 3$ for GWP, which is roughly 2,000 times the cost for the Spread, while the parameter is $9,000 \mathrm{MJ} / \mathrm{m} 3$ for Energy, i.e. less than 1,000 times the cost for the Spread. The algorithm seeks to minimize this treatment by minimizing the embankment. For this reason, optimized profiles are lower in altitude than the reference profile and GWP-optimized profiles are lowest in altitude (see Figure 9). This Sloop behavior is due to local conditions at the worksite. If the soil does not require any treatment, the optimized solutions will differ.

As a consequence, generation of the optimized profile according to GWP would create too many cuts; this profile cannot be built directly. One solution consists of adding a constraint to the optimization problem in order to exclude this type of unbalanced solution. However, in this practical case, the optimized profile according to energy is also significantly better than the reference profile in terms of GWP, showing a gain of $8 \%$ (see Table6). Hence, we did not attempt to improve the optimization problem but rather selected this profile as an alternative to the actual one for the GWP criterion as well. Subsequent analyses will focus on this optimized energy-based profile.

The optimized profile according to energy is well balanced in terms of fill and cut and moreover is compliant with the constraints of an actual construction project (see Figure 9).

We have remarked that the construction gains are derived from minimizing soil treatment, but what are the actual sources of gains during the operations phase? The answers are displayed in 
Table 7. Comparison by class of vehicle (TJ: Tera Joules, teqCO $\mathrm{CO}_{2}$ : metric ton equivalent $\mathrm{CO}_{2}$ )

\begin{tabular}{crrrrrr}
\hline & \multicolumn{3}{c}{ Reference } & \multicolumn{3}{c}{ Optimized } \\
\hline Vehicle & $\begin{array}{r}\text { Energy } \\
(\mathrm{TJ})\end{array}$ & $\begin{array}{r}\mathrm{GWP} \\
\left(\mathrm{teqCO}_{2}\right)\end{array}$ & $\begin{array}{c}\text { fuel } \\
\left(\mathrm{l} \times 10^{6}\right)\end{array}$ & $\begin{array}{r}\text { Energy } \\
(\mathrm{TJ})\end{array}$ & $\begin{array}{r}\text { GWP } \\
\left(\text { teqCO }_{2}\right)\end{array}$ & $\begin{array}{c}\text { fuel } \\
\left(1 \times 10^{6}\right)\end{array}$ \\
\hline Articulated vehicle (40t) & 102.7 & 7899 & 2.64 & 92.2 & 7089 & 2.37 \\
Articulated vehicle (25t) & 78.2 & 6014 & 2.01 & 75.2 & 5786 & 1.94 \\
Truck & 117.18 & 9010 & 3.02 & 106.7 & 8207 & 2.75 \\
Gasoline car & 63.9 & 4871 & 1.83 & 63.8 & 4858 & 1.82 \\
small class diesel car & 13.6 & 1050 & 0.35 & 13.5 & 1037 & 0.35 \\
medium class diesel car & 41.8 & 3215 & 1.07 & 41.8 & 3214 & 1.07 \\
high class diesel car & 37.8 & 2905 & 0.97 & 37.9 & 2915 & 0.97 \\
mini-truck & 19.1 & 1468 & 0.49 & 18.9 & 1454 & 0.48 \\
small Van & 22.6 & 1739 & 0.58 & 22.4 & 1727 & 0.58 \\
Global & 497.0 & 38174 & 12.99 & 472.6 & 36291 & 12.3 \\
\hline
\end{tabular}

Table 7, which presents, for each vehicle class, the primary energy, fuel consumption and corresponding GWP calculated on a 10-year basis for both the reference profile and the profile optimized according to energy. The last row of this table lists the global values of energy consumption or GWP for all vehicles. The global gains of $6 \%$ Energy and $8 \%$ GWP are mainly due to articulated vehicles and trucks. This finding is explained by the fact that the optimized profile tends to limit the longitudinal slope (up and down) and then the energy dissipated during the braking phases.

\subsection{Applicability of Sloop to other projects}

This methodology offers new perspectives to stakeholders by raising awareness about the environmental impact of the operations phase due to the longitudinal profile. This methodology however cannot bring significant improvements to a constrained area like the mountains or a zone without slopes like flat plains.

We have proven the applicability of this methodology to a real case study but on a relatively small section (the optimized length is $4.75 \mathrm{~km}$ ). For large projects, the number of degrees of freedom increases and the optimization is more complex the longer the computation time.

\subsection{Hypotheses and limits of Sloop}

Sloop results depend on traffic assumptions, i.e. number and type of vehicles. In our case study, we have limited the traffic evolution to 10 years. Moreover, since we are focusing on an actual road, we were able to carry out real traffic measurements and obtained accurate readings. It is very difficult to guess the nature of the traffic after 10 years, in particular with the development of electric vehicles. The prediction of the number of vehicles that will be traveling on the road depends on various exogenous factors like economic growth, fuel cost, regulations and, more generally, transportation policy (taxes, new infrastructure, etc.). From this perspective, the methodology remains valuable in testing various traffic evolution scenarios. 
In general, Sloop yields results without an indication of uncertainty. Two major sources of uncertainty are:

- the assumptions adopted on traffic and its evolution: further investigation is needed to test the optimization algorithm with more complex traffic assumptions;

- characteristics of the natural soil: if the initial material has to be treated, then the cost in terms of GWP is higher. This specific problem can be addressed by carrying out geotechnical measurements or by computing the effect of this unknown factor on the uncertainty of the optimized solution.

Beyond this initial work effort, a complete sensitivity study will be carried out in the near future in order to assess uncertainty.

The optimization with just one criterion oversimplifies the problem and can lead to unrealistic solutions. One perspective calls for carrying out a multi-criteria optimization in order to propose a set of efficient solutions (a Pareto front) to stakeholders. The decision to choose among these solutions is left up to the stakeholders. These algorithms serve to remove inefficient solutions. Decision-makers can then focus on relevant solutions.

The initial number of sections is fixed by the initial longitudinal profile. This parameter could be another degree of freedom for the optimization program. It is difficult however to take this parameter into account in the optimization program, whose number of degrees of freedom remains quite high.

\section{Conclusion}

This paper presented a methodology for optimizing the longitudinal road profile from a Life Cycle Assessment perspective. Two environmental indicators, namely primary energy consumption and GWP, have been considered in the analysis. The objective here is to minimize either energy or GHG emissions during both the construction and operations phases. This optimization protocol is based on models describing these two phases.

The model of the construction phase is based on:

- standard geometric models for natural soil and the road project; a comparison of the two models provides the basis of the earthmoving analysis; the earthmoving task is assessed using actual measurements of earthworks equipment fuel consumption;

- soil treatment.

The model of the operation phase is based on:

- dynamic models for the different types of vehicles; from dynamic models, the engine models provide fuel consumption and emissions;

- a 10-year traffic estimate; this estimate is calculated from actual traffic measurements. 
These dynamic models have been validated during previous research work. They were selected in considering their accuracy, reliability and capability of assessing the effect of longitudinal profile on energy consumption and GWP.

This methodology was then applied to a real case study. With our assumptions of traffic evolution over 10 years, the optimized profile features a $6 \%$ decrease in the primary energy consumption and a $8 \%$ drop in the GWP impact. These results are indeed significant and can be explained by mechanical considerations. For example, the optimized solution mitigates the braking of trucks during a downhill descent.

These valuable results provide a new perspective for decision-makers by raising awareness about the environmental impacts of the operations phase due to the longitudinal profile.

\section{References}

AASHTO , 1994. A policy on geometric design of highway and streets. Tech. rep., AASHTO : American Association of State Highway and Transportation Officials, Washington DC, USA.

Bosquet, R., Jullien, A., Vandanjon, P.-O., Dauvergne, M., Sanchez, F., Dec. 2014. Eco-design model of a railway: A method for comparing the energy consumption of two project variants. Transportation Research Part D: Transport and Environment 33, 111-124.

Bryce, J., Santos, J., Flintsch, G., Katicha, S., McGhee, K., Ferreira, A., 2014. Asphalt Pavement. CRC Press, Ch. Analysis of rolling resistance models to analyse vehicle fuel consumption as a function of pavement properties, pp. 263-273.

Capony, A., Muresan, B., Dauvergne, M., Auriol, J. C., Ferber, V., Jullien, A., Jan. 2013. Monitoring and environmental modeling of earthwork impacts: A road construction case study. Resources, Conservation and Recycling 74, pp.124-133.

CCFA, 2017. French automotive industry: Analysis and statistics. report, Comité des Constructeurs Français d'Automobiles, Paris, France.

Chew, E., Goh, C., Fwa, T., 1989. Simultaneous optimization of horizontal and vertical alignments for highway. Transportation Research Part B: Methodological 23B, 395-328.

Davey, N., Dunstall, S., Halgamuge, S., 2017. Optimal road design through ecologically sensitive areas considering animal migration dynamics. Transportation Research Part C: Emerging Technologies 77, 478-494.

EU, 2010. Official journal of the european union : Regulation no 101 of the economic commission for europe of the united nations (un/ece). https://eur-lex.europa.eu/legal-content/en/txt/?uri=celex, European Union.

Hammarström, U., Eriksson, J., Karlsson, R., Yahya, M. R., 2012. Rolling resistance model, fuel consumption model and the traffic energy saving potential from changed road surface conditions. Statens väg-och transportforskningsinstitut.

Huang, W., Bevly, D., Schnick, S., Li, X., Oct. 2008. Using 3d road geometry to optimize heavy truck fuel efficiency. In: 11th International IEEE Conference on Intelligent Transportation Systems, 2008. ITSC 2008. pp. 334-339.

IPCC, 2007. Fourth assessment report, climate change: the physical science basis. chapter 2: changes in atmospheric constituents and radiative forcing. Ipcc, Intergovernmental Panel on Climate Change, Geneva, Switzerland.

ISO, 2006a. Environmental management - life cycle assessment - principles and framework, 14040:2006. ISO 14040:2006, International Organization for Standardization, Geneva, Switzerland.

ISO, 2006b. Environmental management - life cycle assessment - requirements and guidelines, 14044:2006. ISO 14044:2006, International Organization for Standardization, Geneva, Switzerland.

ITF, 2017. ITF Transport Outlook 2017. Tech. rep., ITF, ISBN: 978-92-82-10799-7.

Jeanneret, B., Trigui, R., Badin, F., Harel, F., Damemme, F., Lavy, J., 1999. New hybrid concept simulation tools, evaluation on the toyota prius car. In: EVS 16th international Electric Vehicle symposium, October 13-16,1999, Beijing, China. pp. 1-11.

Jha, M. K., Schonfeld, P. M., Jong, J.-C., Kim, E., 2006. Intelligent Road Design. WIT Press, ISBN:978-1-84564-003-3.

Jong, J.-C., Schonfeld, P., 2001. An evolutionary model for simultaneously optimizing three-dimensional highway alignments. Transportation Research Part B: Methodological 37, 107-128. 
Jullien, A., Cerezo, V., Keijzer, E., Lòpez, A.-M., Dauvergne, M., Muresan Paslaru, B., Giezen, C., Fernando Florez, R., 2015a. Deliverable d1.4: benchmarking exercise to assess the set of proposed indicators in diverse road case studies, lce4roads european project. Tech. rep., IFSTTAR, Nantes, France.

Jullien, A., Dauvergne, M., Proust, C., 2015b. Road LCA: the dedicated ECORCE tool and database. International Journal of Life Cycle Assessment 20, 655-670.

Kamal, M., Mukai, M., Murata, J., Kawabe, T., Sep. 2011. Ecological Vehicle Control on Roads With Up-Down Slopes. IEEE Transactions on Intelligent Transportation Systems 12 (3), 783-794.

Kang, M.-W., Jha, M. K., Schonfeld, P., 2011. Applicability of highway alignment optimization models. Transportation Research Part C: Emerging Technologies 21, 257-286.

MEEM, 2017. Chiffres clés du transport - édition 2017. Tech. rep., MEEM : French Ministry of Environment, Energy and Sea., La Défense, Paris, France.

Meyer, L., Brinkman, S., van Kesteren, L., Leprince-Ringuet, N., van Boxmeer, F., 2014. IPCC, 2014: Climate Change 2014: Synthesis Report. Contribution of Working Groups I, II and III to the Fifth Assessment Report of the Intergovernmental Panel on Climate Change, 3-87.

Monge, G., 1781. Mémoire sur la théorie des déblais et des remblais. In: Histoire de l'Académie royale des sciences. Imprimerie royale, pp. 666-705.

Ragione, L. D., Giovanni, M., 2016. The influence of road gradient in an integrated approach of real driving cycles and emissions factors model. Transportation Research Procedia, TRA-2016 14, 3179 - 3188.

Sentoff, K. M., Aultman-Hall, L., Holmén, B. A., Mar. 2015. Implications of driving style and road grade for accurate vehicle activity data and emissions estimates. Transportation Research Part D: Transport and Environment 35, $175-188$

Setra, 2000. ICTAAL - French technical reference document for design of motorways in interurban areas, divided carriageway roads, with at least two lanes in the link sections (in French). Setra, France.

Vinot, E., Scordia, J., Trigui, R., Jeanneret, B., Badin, F., 2008a. Model simulation, validation and case study of the 2004 ths of toyota prius. International Journal of Vehicle Systems Modelling and Testing 3 (3), 139-167.

Vinot, E., Trigui, R., Jeanneret, B., Scordia, J., 2008b. A complete set of tools for hybrid vehicle design : from cybernetics model to hardware in the loop simulation. In: Les rencontres scientifique de l'IFP-Advances in Hybrid Powertrains , 2008.

Wang, H., Thakkar, C., Chen, X., Murrel, S., 2016. Life-cycle assessment of airport pavement design alternatives for energy and environmental impacts. Journal of Cleaner Production 133, $163-171$. URL http: //www. sciencedirect.com/science/article/pii/S0959652616305546

Webb, C., 1952. The effect of gradient on fuel consumption and speed of a road vehicle. Proceedings of the Institution of Mechanical Engineers, Part E 3.

Wyatt, D. W., Li, H., Tate, J. E., Oct. 2014. The impact of road grade on carbon dioxide (CO2) emission of a passenger vehicle in real-world driving. Transportation Research Part D: Transport and Environment 32, 160-170.

\section{Appendix A. Elementary volume computation}

In this Appendix, the elementary volume corresponding to Figure 4 is computed. The mathematical computation of the elementary volume $\mathrm{V}$, is performed by integrating of a trapezoid from the beginning of the segment, with an initial index $i$, to the end, denoted by a final index $f$. This integration step yields the following result:

$$
\mathrm{V}=\frac{1}{2}\left(\frac{\mathrm{d}}{3} \Delta \mathrm{h}\left(\Delta \mathrm{w}_{\mathrm{ph}}+\Delta \mathrm{w}_{\mathrm{pb}}\right)+\frac{\mathrm{d}}{2}\left(\mathrm{~h}_{i} \Delta \mathrm{w}_{\mathrm{ph}}+\mathrm{w}_{\mathrm{ph}_{i}} \Delta \mathrm{h}+\mathrm{h}_{i} \Delta \mathrm{w}_{\mathrm{pb}}+\mathrm{w}_{\mathrm{pb}_{i}} \Delta \mathrm{h}\right)+\mathrm{d} \times \mathrm{h}_{i}\left(\mathrm{w}_{\mathrm{ph}_{i}}+\mathrm{w}_{\mathrm{pb}_{i}}\right)\right)
$$

The height, $\mathrm{h}_{i}$, is the difference in altitude between the natural terrain and the road project at the beginning of the segment. $\mathrm{h}_{i}=\operatorname{Ps}\left(\mathrm{x}_{i}\right)-\operatorname{Pn}\left(\mathrm{x}_{i}\right)$ where $\mathrm{x}_{i}$ is the position of the initial segment 
point, $\mathrm{h}_{f}$ is calculated as $\mathrm{h}_{i}$ but at the end of the segment (at the metric point $\mathrm{x}_{f}$ ). $\mathrm{w}_{\mathrm{ph}}$, is the width on top of the formation level at the beginning of the segment, and, $\mathrm{w}_{\mathrm{ph}_{f}}$, is the same at the end. $\mathrm{w}_{\mathrm{pb}_{i}}$ is the width of the basis of the formation level at the beginning of the segment line. It is computed from $\mathrm{h}_{i}$ and the slope $\mathrm{s}_{\mathrm{b} i}$ of the bank, $\mathrm{w}_{\mathrm{pb}}$ is computed at the end of the segment. The differences are symbolized by $\Delta: \Delta \mathrm{h}=\mathrm{h}_{f}-\mathrm{h}_{i}, \Delta \mathrm{w}_{\mathrm{ph}}=\mathrm{w}_{\mathrm{ph}_{f}}-\mathrm{w}_{\mathrm{ph}_{i}}, \Delta \mathrm{w}_{\mathrm{pb}}=\mathrm{w}_{\mathrm{pb}_{f}}-\mathrm{w}_{\mathrm{pb}_{i}}$. The discretization step, $d$, is chosen by the surveyor. Equation A.1 remains unchanged in the case of an excavation, with $\mathrm{V}$ simply becoming the earth volume to be extracted.

For the sake of clarity, we have only presented the computation of the volume corresponding to the simplest embankment cross section in Figure 4. The volume computations were performed for all types of cross-sections, as described in Figure 5 by conducting the same method. 


\section{Appendix B. Notation}

The following symbols have been used in this paper:

$\mathrm{d}=$ step of discretization of the longitudinal profile $(\mathrm{m})$;

$\mathrm{e}_{\mathrm{cnu}}=$ the energy consumption by cubic meter spread on a final deposit $\left(\mathrm{J} / \mathrm{m}^{3}\right)$;

$\mathrm{e}_{\mathrm{f}}=$ the energy consumption by cubic meter for fill $\left(\mathrm{J} / \mathrm{m}^{3}\right)$;

$\mathrm{e}_{\text {lime }}=$ energy consumption of one cubic meter of quicklime $\left(\mathrm{J} / \mathrm{m}^{3}\right)$;

$e_{t}=$ the energy consumption by cubic meter for cutting in order to build trench $\operatorname{road}\left(\mathrm{J} / \mathrm{m}^{3}\right)$;

$\mathrm{e}_{\text {extrac }}=$ the energy consumption by cubic meter in order to extract material $\left(\mathrm{J} / \mathrm{m}^{3}\right)$;

$\mathrm{e}_{\text {trans }}=$ energy cons. for transport. of one cubic meter of mat. on 1 kilometer $\left(\mathrm{J} / \mathrm{m}^{3} / \mathrm{km}\right)$;

$\mathrm{e}_{\text {spread }}=$ energy consumption in order to spread one cubic meter of materials $\left(\mathrm{J} / \mathrm{m}^{3}\right)$;

$\operatorname{gwp}_{\mathrm{cnu}}=$ GWP by cubic meter for cutting not used and spread on a final deposit $\left(\mathrm{kgeqCO} / \mathrm{m}^{3}\right)$;

gwp $_{\mathrm{f}}=$ GWP by cubic meter for fill $\left(\mathrm{kgeqCO}{ }_{2} / \mathrm{m}^{3}\right)$;

gwp $_{\mathrm{t}}=$ GWP by cubic meter for cutting in order to build trench road $\left(\mathrm{kgeqCO} \mathrm{CO}_{2} / \mathrm{m}^{3}\right)$;

gwp $_{\text {extrac }}=$ GWP by cubic meter in order to extract material $\left(\mathrm{kgeqCO} / 2 \mathrm{~m}^{3}\right)$;

gwp $_{\text {trans }}=$ GWP for transport. of one cubic meter of mat. on 1 kilometer $\left(\mathrm{kgeqCO}_{2} / \mathrm{m}^{3} / \mathrm{km}\right)$;

$\operatorname{gwp}_{\text {spread }}=$ GWP in order to spread one cubic meter of materials $\left(\mathrm{kgeqCO} / \mathrm{m}^{3}\right)$;

gwp $_{\text {lime }}=$ GWP of one cubic meter of quicklime $\left(\mathrm{kgeqCO}_{2} / \mathrm{m}^{3}\right)$;

$\mathrm{h}=$ the difference of altitude between the natural terrain and the road project $(\mathrm{m})$;

$\mathrm{m}=$ mass of the vehicle $(\mathrm{kg})$

$n=$ number of straight lines;

$\mathrm{r}_{\text {limeC }}=$ rate of quicklime of the treated materials stored in final deposit (\%);

$\mathrm{r}_{\text {limeF }}=$ rate of quicklime of the treated materials for fill $(\%)$;

$\mathrm{s}_{\mathrm{b}}=$ transversal slope of the embankment (\%);

$\mathrm{v}=$ speed of the vehicle $(\mathrm{m} / \mathrm{s})$;

$\mathrm{w}_{\mathrm{ph}}=$ the width of top of the formation level $(\mathrm{m})$;

$\mathrm{w}_{\mathrm{pb}}=$ the width of the basis of the formation level (m);

$\mathrm{x}=$ longitudinal abscissa $(\mathrm{m})$;

$C_{r r 0}=$ constant part of the tire rolling resistance;

$C_{r r 1}=$ part of the tire rolling resistance proportional to speed $\left(s \cdot m^{-1}\right)$;

$C_{x}=$ Drag coefficient;

Dist $_{\mathrm{D}}=$ average distance between cut and final deposit $(\mathrm{km})$;

Dist $_{\mathrm{FC}}=$ average distance between cut and fill $(\mathrm{km})$;

$\mathrm{E}=$ primary energy consumption of the project $(\mathrm{J})$;

$\mathrm{E}_{\mathrm{c}}=$ primary energy consumption of the construction phase $(\mathrm{J})$;

$\mathrm{E}_{\mathrm{f}}=$ primary energy consumption of fill $(\mathrm{J})$;

$\mathrm{E}_{\text {AddMat }}=$ energy consumption due to additional materials $(\mathrm{J})$;

$\mathrm{F}_{\mathrm{t}}=$ traction force $(\mathrm{N})$;

$\mathrm{F}_{\mathrm{r}}=$ running resistance $(\mathrm{N})$;

$F C=$ Fuel Consumption; 


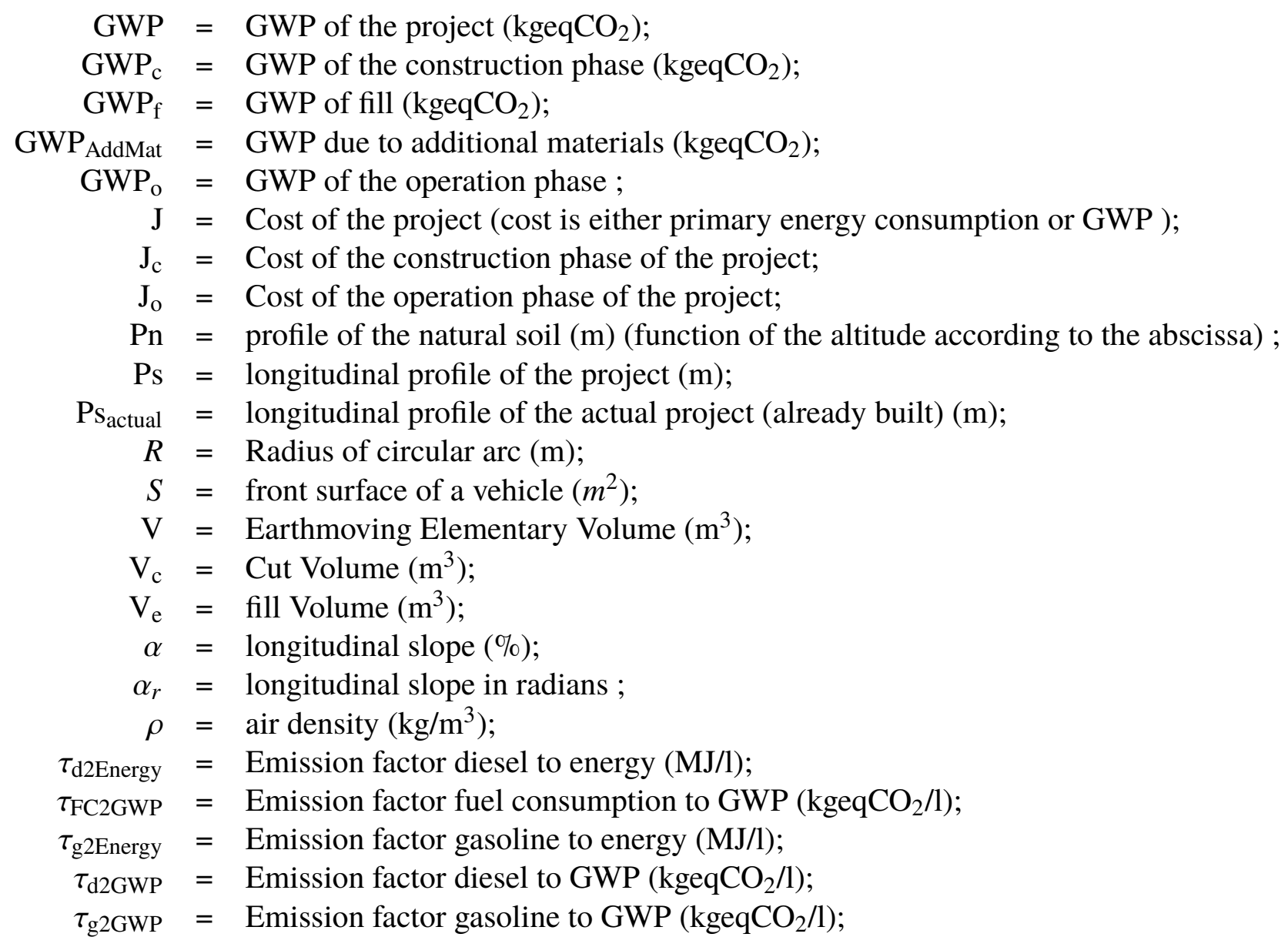

\section{Appendix C. Funding statement}

This research did not receive any specific grant from funding agencies in the public, commercial, or nonprofit sector. The study was conducted with funding from the authors' respective institutes (Ifsttar and Cerema, France).

\section{Appendix D. Data Availability Statements}

Construction and Traffic data have been included in this paper.

Vehicle consumption data are generated from the software, VEHLIB, which is not open source; nonetheless, the main parameters of the simulation carried out with this software have been displayed herein. All Data generated are available from the corresponding author upon request. 